\title{
On the submicron aerosol distributions and CCN number concentrations in and around the Korean Peninsula
}

\author{
J. H. Kim ${ }^{1}$, S. S. Yum ${ }^{1}$, S. Shim ${ }^{1}$, W. J. Kim ${ }^{1}$, M. Park ${ }^{1}$, J.-H. Kim ${ }^{2}$, M.-H. Kim ${ }^{2}$, and S.-C. Yoon ${ }^{2}$ \\ ${ }^{1}$ Department of Atmospheric Sciences, Yonsei University, Seoul, South Korea \\ ${ }^{2}$ School of Earth and Environmental Sciences, Seoul National University, Seoul, South Korea \\ Correspondence to: S. S. Yum (ssyum@yonsei.ac.kr)
}

Received: 27 January 2014 - Published in Atmos. Chem. Phys. Discuss.: 25 March 2014

Revised: 9 July 2014 - Accepted: 13 July 2014 - Published: 26 August 2014

\begin{abstract}
Total number concentrations of particles having a diameter larger than $10 \mathrm{~nm}\left(N_{\mathrm{CN}}\right)$, cloud condensation nuclei at several supersaturation $(S)$ values $\left(N_{\mathrm{CCN}}\right)$ and number size distributions of particles with 10-414 nm diameter were measured in Seoul between 2004 and 2010. Overall average values of $N_{\mathrm{CN}}$ and geometric mean diameter were $17811 \pm 5581 \mathrm{~cm}^{-3}$ and $48 \pm 6 \mathrm{~nm}$. Average $N_{\mathrm{CCN}}$ at $0.4,0.6$ and $0.8 \% \mathrm{~S}$ were $4145 \pm 2016,5323 \pm 2453$ and $6067 \pm 2780 \mathrm{~cm}^{-3}$ and corresponding $N_{\mathrm{CCN}} / N_{\mathrm{CN}}$ were $0.26 \pm 0.11,0.33 \pm 0.11$ and $0.37 \pm 0.12$. There is a clear seasonal variation in aerosol concentration, which seems to be due to the monsoon. $N_{\mathrm{CN}}$ and $N_{\mathrm{CCN}}$ are also found to depend on the volume of traffic and the height of the planetary boundary layer, respectively.

During aircraft campaigns in 2009 and 2011, $N_{\mathrm{CN}}$ and $N_{\mathrm{CCN}}$ at $0.6 \% \mathrm{~S}\left(N_{0.6 \%}\right)$ were measured in and around the Korean Peninsula. During the 2011 campaign, the aerosol scattering coefficient was also measured. $N_{\mathrm{CN}}$ and $N_{0.6 \%}$ in the lower altitudes were generally higher than at higher altitudes, except for cases when particle formation and growth events were thought to occur at higher altitudes. $N_{\mathrm{CN}}$ and $N_{0.6 \%}$ generally show a positive correlation with aerosol scattering coefficients but this correspondence tends to vary with altitude. Occasional instances of low $(<0.3)$ $N_{0.6 \%} / N_{\mathrm{CN}}$ in the boundary layer are demonstrated to be associated with particle formation and growth events. With the support of ground measurements, it is confirmed that a particle formation and growth event did indeed occur over the Yellow Sea on a flight day, and the areal extent of this event is estimated to be greater than $100 \mathrm{~km} \times 450 \mathrm{~km}$.

With the combination of the current and several relevant previous studies, a composite map of $N_{\mathrm{CN}}$ and $N_{\mathrm{CCN}}$ in and
\end{abstract}

around the Korean Peninsula is produced. Overall, the exhibited concentrations are typical of values measured over polluted regions elsewhere on the globe. Moreover, there is a generally decreasing trend from west to east over the region, implying that the region is constantly under the dominant influence of continental outflow.

\section{Introduction}

With increasing attention to climate change, interest in cloud condensation nuclei (CCN) has not been limited to the cloud physics community due to $\mathrm{CCN}$ effects on various cloud properties, including cloud albedo and lifetime (i.e., aerosol indirect effects, AIE). Interest is widespread throughout atmospheric science, climate science and aerosol science communities. With increasing fear that societies are not adopting necessary measures to prevent catastrophic climate change quickly enough (Rogelj et al., 2011), AIE has also sparked debate about so-called "geo-engineering" (Crutzen, 2006; Robock, 2008).

AIE has attracted many researchers not only because its magnitude is estimated to be large enough to compensate for a significant portion of the greenhouse gas effect but also because of its large uncertainty (IPCC, 2007), especially for determining climate sensitivity (Kiehl, 2007; Schwartz et al., 2010). One reason for such large uncertainty is that aerosol properties exhibit high geographical heterogeneity due to short atmospheric lifetime (days) compared to greenhouse gases (years) (IPCC, 2007). Such heterogeneity makes it difficult for scientists to draw a global and long-term picture of aerosol contributions. Therefore, securing aerosol data sets 
of global coverage is important, especially with regard to the number concentration, which is of primary concern when it comes to cloud and aerosol interaction because the number of cloud droplets is initially determined by the number of aerosol particles that can be activated as embryonic cloud droplets at a given supersaturation (S). Such information is relatively scarce in East Asia compared to Europe and North America (Kumala et al., 2004), although various efforts have been made in recent years, including those that tried to characterize new particle formation (Weber et al., 2003; Buzorius et al., 2004; McNaughton et al., 2004; Wu et al., 2007; Lee et al., 2008; Park et al., 2008; Wiedensohler et al., 2009; Song et al., 2010; Kim et al., 2012, 2013) and CCN properties (Matsumoto et al., 1997; Adhikari et al., 2005; Yum et al., 2005, 2007; J. H. Kim et al., 2011; Kuwata and Kondo, 2008; Kuwata et al., 2008; Mochida et al., 2010; Rose et al., 2010).

This study is an addition to those efforts and aims to characterize the number concentration of submicron particles (i.e., condensation nuclei, $\mathrm{CN})\left(N_{\mathrm{CN}}\right)$ and $\mathrm{CCN}$ concentration $\left(N_{\mathrm{CCN}}\right)$ measured in and around the Korean Peninsula, which is located about $500 \mathrm{~km}$ downwind of China (considering the prevailing westerly winds in this region) and therefore suitable for monitoring continental outflow firsthand.

This study first focuses on aerosol and CCN characteristics measured in Seoul, which represents a typical large urban area in East Asia. About 1000 and 800 days, respectively, of CN and CCN data, covering 2004-2010, are analyzed in order to provide statistically robust results. It is suggested that while the majority of $\mathrm{CN}$ observed in Seoul had a local origin, the same could not be said for CCN.

We then present $\mathrm{CN}$ and $\mathrm{CCN}$ data observed during two aircraft measurement campaigns in and around the Korean Peninsula. To our knowledge, these are the first attempts to record such data over the Korean Peninsula. The main purpose of these campaigns was to verify from in situ measurements whether there really are east-west gradients of aerosol concentrations in continental outflow regions as exemplified by Y.-J. Kim et al. (2011), who showed a smoothly decreasing trend of aerosol optical depth (AOD) from China to the East Sea by averaging the satellite-retrieved AOD data of several years. Vertical profiles of $N_{\mathrm{CN}}$ and $N_{\mathrm{CCN}}$ measured during the two campaigns varied a lot but concentrations were generally higher in the planetary boundary layer (PBL) than the free troposphere, and the concentrations in the PBL were higher over the Yellow Sea than over the East Sea, demonstrating that the east-west gradient is indeed present.

Lastly, we provide a composite map of $N_{\mathrm{CN}}$ and $N_{\mathrm{CCN}}$ in the PBL in and around the Korean Peninsula by combining data presented in this study with data from several previous measurement studies on various platforms within this region: rural sites (Yum et al., 2005; Kim et al., 2012), island sites (Yum et al., 2007; J. H. Kim et al., 2011) and research vessels (Kim et al., 2009). Statistically robust results from Seoul enabled us to distinguish characteristics that may be similar to those of other regions within the Korean Peninsula from those arising from local sources in Seoul. Aircraft measurements provided data at locations that ground measurements could not cover, such as the Yellow Sea and the East Sea. This map is the product of 8 years of effort to measure the aerosol size distribution and $N_{\mathrm{CCN}}$ within the PBL over this region. Considering the fact that aerosol concentrations, especially $N_{\mathrm{CCN}}$, did not vary much within the PBL as shown in this study, these concentrations should be highly relevant to the droplet concentrations of clouds with bases within the PBL. Therefore, this composite map is expected to be greatly used as a valuable reference data set for modeling studies and for satellite remote-sensing retrievals of aerosol distributions in East Asia.

\section{Seoul measurement (2004-2010)}

Seoul $\left(37.6^{\circ} \mathrm{N}, 127.0^{\circ} \mathrm{E}\right)$ is a megacity of more than 10 million people. Owing to numerous anthropogenic sources and large seasonal variations due to the monsoon, Seoul's aerosol properties cannot be characterized from a few intensive campaigns. Here we present long-term measurements from 2004 to 2010 .

\subsection{Method}

$N_{\mathrm{CN}}$ and submicron aerosol size distributions by TSI CPC3010 $\left(D_{\mathrm{p}}>10 \mathrm{~nm}\right)$ and TSI SMPS (Scanning Mobility Particle Sizer) 3936L10 $\left(10 \mathrm{~nm}<D_{\mathrm{p}}<414 \mathrm{~nm}\right)$, respectively, were measured at the Yonsei University campus located in the northwestern part of Seoul. The instruments were placed in a sixth-floor room of a building on the campus, which is about $300 \mathrm{~m}$ from major roads outside the campus and therefore safely removed from the immediate influence of traffic emissions to the campus. The data were obtained every 1 and $180 \mathrm{~s}$ for $\mathrm{CN}$ and aerosol size distributions, respectively, and accumulated from June and September 2004, respectively, until the end of December 2010. Due to very high $N_{\mathrm{CN}}$ in Seoul, the sample air for $N_{\mathrm{CN}}$ was diluted by splitting the sample flow into two branches and passing one of them through a HEPA filter to remove all particles and then combining it with the other branch before feeding it into the instrument. The flow of each branch was measured every 1 or 2 weeks and the resulting dilution factor was mostly between 2.5 and 3.0. $N_{\mathrm{CCN}}$ measurement started at the same site from September 2006 with a single column CCN counter (CCNC) from Droplet Measurement Technologies. This instrument produced data every $1 \mathrm{~s}$ and was calibrated with the method illustrated by J. H. Kim et al. (2011).

Because the instruments had to be deployed for various field campaigns (e.g., Yum et al., 2005, 2007; Kim et al., 2009, 2012; J. H. Kim et al., 2011), a total of 981, 1066 and 797 days of data were collected for $N_{\mathrm{CN}}$, aerosol size distribution and $N_{\mathrm{CCN}}$, respectively, which cover about $41-50 \%$ 


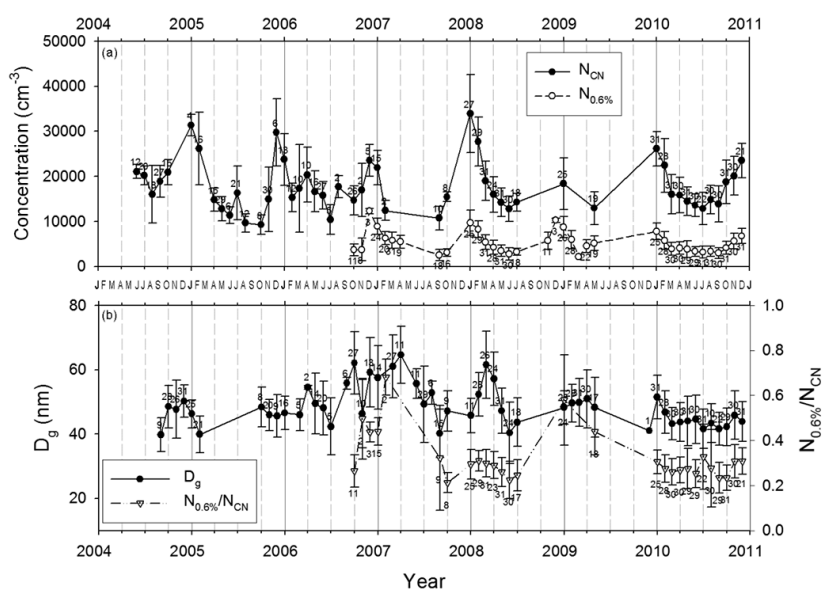

Figure 1. Time variation of the monthly average values of (top) $N_{\mathrm{CN}}$ and $N_{0.6 \%}$, and (bottom) $D_{\mathrm{g}}$ and $N_{0.6 \%} / N_{\mathrm{CN}}$ measured in Seoul. The numbers near each symbol indicate the number of measurement days for the month. Error bars for $N_{0.6 \%}$ and $N_{0.6 \%} / N_{\mathrm{CN}}$ indicate the standard deviation.

of the days in the corresponding period. There are more aerosol size distributions than $N_{\mathrm{CN}}$ data due to optical contamination from the Condensation Particle Counter (CPC) that arose from the high level of air pollution in Seoul.

Mean $N_{\mathrm{CN}}$ was obtained by averaging a total of 53 monthly averaged values, each of which is again the average of about 19 daily average values. Average $D_{\mathrm{g}}$ is obtained in a similar fashion, with a total of 52 months and about 20 days for each month. Average $N_{\mathrm{CCN}}$ at $0.4,0.6$ and $0.8 \% \mathrm{~S}$ is from 35 monthly averaged values (about 23 days for each month) and $N_{\mathrm{CCN}} / N_{\mathrm{CN}}$ is from the 28 months (about 22 days each) when $N_{\mathrm{CCN}}$ and $N_{\mathrm{CN}}$ were simultaneously available.

\subsection{Results}

\subsubsection{Overall statistics}

Figure 1 shows the temporal variation of the monthly average values of $N_{\mathrm{CN}}, N_{\mathrm{CCN}}$, geometric mean diameter $\left(D_{\mathrm{g}}\right)$ and $N_{\mathrm{CCN}} / N_{\mathrm{CN}}$. A seasonal variation is obvious as will be discussed in detail below. The average submicron aerosol size distribution for the whole period is shown in Fig. 2. The average values of $N_{\mathrm{CN}}$ and $D_{\mathrm{g}}$ are $17811 \pm 5581 \mathrm{~cm}^{-3}$ and $48 \pm 6 \mathrm{~nm}$. The average $N_{\mathrm{CCN}}$ at $0.4,0.6$ and $0.8 \% \mathrm{~S}\left(N_{0.4 \%}\right.$, $N_{0.6 \%}$ and $\left.N_{0.8 \%}\right)$ are $4145 \pm 2016,5323 \pm 2453$ and $6067 \pm 2780 \mathrm{~cm}^{-3}$, respectively. The corresponding ratios of $N_{\mathrm{CCN}} / N_{\mathrm{CN}}$ are $0.26 \pm 0.11,0.33 \pm 0.11$ and $0.37 \pm 0.12$, respectively.

$N_{\mathrm{CN}}$ measured in Seoul is much lower than $N_{\mathrm{CN}}$ measured in some other megacities of Asia such as New Delhi, India (Mönkkönen et al., 2005), or Beijing, China (Wu et al., 2007). It is comparable to $N_{\mathrm{CN}}$ measured in Guangzhou, China (Rose et al., 2010), and is much higher than $N_{\mathrm{CN}}$ measured in Tokyo, Japan (Kuwata and Kondo, 2008). $N_{\mathrm{CN}}$ is a



Figure 2. Overall average aerosol size distribution in Seoul. The error bars indicate the standard deviation value for each size bin. $35 \mathrm{~nm}$ (vertical dashed line) and $46 \mathrm{~nm}$ (vertical dash-dot line) are the mode diameter and geometric mean diameter of the distribution, respectively.

factor of two higher than $N_{\mathrm{CN}}$ at European rural sites (Asmi et al., 2011). $N_{\mathrm{CCN}}$ is much lower than the $N_{\mathrm{CCN}}$ measured in Beijing (Weidensohler et al., 2009) and Guangzhou, but higher than $N_{\mathrm{CCN}}$ measured in Tokyo.

Figure 3 is the scatterplot of simultaneously measured, hourly averaged $D_{\mathrm{g}}$ vs. $N_{0.6 \%} / N_{\mathrm{CN}}$ that shows a strong positive correlation. Interpreting $N_{0.6 \%} / N_{\mathrm{CN}}$ as an average probability of randomly selected particles acting as CCN (for some data in Fig. 3 this value exceeds 1, due to instrumental differences between the TSI CPC 3010 and the Droplet Measurement Technologies (DMT) CCNC) and $D_{\mathrm{g}}$ as its average diameter, it can be said that the sizes of the particles is determined the $\mathrm{CCN}$ activity to a certain degree. However, it should also be pointed out that $N_{0.6 \%} / N_{\mathrm{CN}}$ values vary significantly for a constant $D_{\mathrm{g}}$ in Fig. 3, especially for the diameter range of $40-70 \mathrm{~nm}$. This implies that while the size may have been the primary factor for determining whether particles would act as $\mathrm{CCN}$, there were other factors (e.g., chemical composition) that affected the $\mathrm{CCN}$ activity of particles in Seoul.

\subsubsection{Seasonal variation}

Monthly average values of $N_{\mathrm{CN}}, N_{0.4 \%}, N_{0.6 \%}, N_{0.8 \%}$, $N_{\mathrm{CCN}} / N_{\mathrm{CN}}$ and $D_{\mathrm{g}}$ are shown in Fig. $4 \mathrm{~b}$ and c. The values are first daily averaged and then averaged for the month of each year. The number of monthly measurement days for each instrument is also shown in Fig. $4 \mathrm{a} . N_{\mathrm{CN}}$ and $N_{\mathrm{CCN}}$ during the winter (December-February) are double those during the summer (June-July). It may be suspected that wintertime heating emissions may have contributed to the high wintertime concentrations. However, $N_{\mathrm{CN}}$ and $N_{\mathrm{CCN}}$ were not especially higher on colder days when more heating was expected (not shown). Therefore, the higher wintertime concentrations cannot easily be attributed to emission from heating. The seasonal variation of $N_{\mathrm{CN}}$ and $N_{\mathrm{CCN}}$ can be 


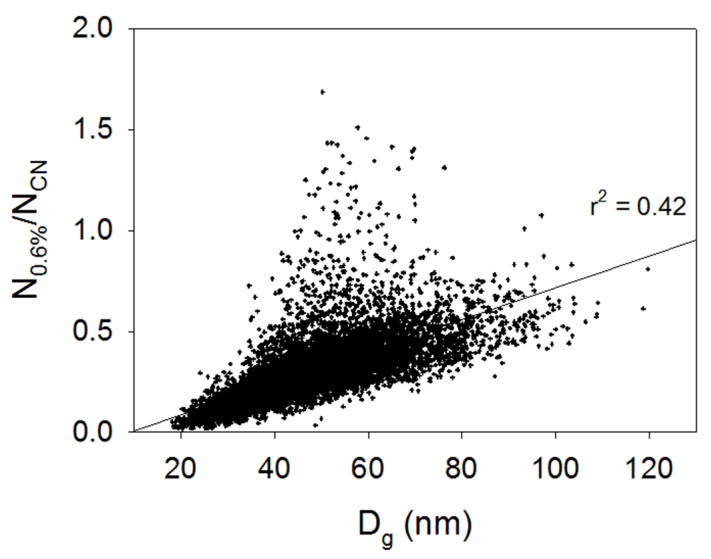

Figure 3. Scatterplot of $D_{\mathrm{g}}$ vs. $N_{0.6 \%} / N_{\mathrm{CN}}$ for hourly averaged data in Seoul. Occasionally the ratio exceeds 1 , due to instrumental differences between TSI CPC 3010 and DMT CCNC. Total number of data was 11339 .

attributed to the monsoon that generally brings continental air during winter and maritime air to the Korean Peninsula from the Pacific during summer. The monsoon also brings more than half of the annual Seoul precipitation during the summer. However, negligible correlation is found between $N_{\mathrm{CCN}}$ or $N_{\mathrm{CN}}$ and daily precipitation amounts for the summer months. This reduces the possibility that the low concentrations during summer months are solely due to precipitation scavenging. Even on the record-breaking day of $259 \mathrm{~mm}$ precipitation (21 September 2010), $N_{\mathrm{CN}}$ and $N_{0.6 \%}$ are close to $70 \%$ of the average values for that month and there were other days in that month exhibiting even lower concentrations.

In Fig. $4 \mathrm{c}, D_{\mathrm{g}}$ is the largest in March and April when Asian dust events are the most frequent (Kim, 2008). This implies that the sizes of submicron particles in Seoul were being affected by these events. The largest $D_{\mathrm{g}}$, however, does not result in the highest $N_{\mathrm{CCN}} / N_{\mathrm{CN}}$ for these 2 months, as might be expected from Fig. 3. This means that the particle sizes were the largest but their hygroscopicity was lower during these two months. This explains the large vertical spread of $N_{\mathrm{CCN}} / N_{\mathrm{CN}}$ for a constant $D_{\mathrm{g}}$ in Fig. 3. For each CCN spectrum obtained every $30 \mathrm{~min}$, the parameter $k$ for the relationship $\mathrm{N}_{\mathrm{CCN}}=\mathrm{C} \times S^{k}$ (where $C$ is $N_{1} \%$ ), known as the "Twomey relationship", was calculated, and its monthly averaged values are shown in Fig. 4c. Parameter $k$ is the slope of the CCN spectrum in log-log plot for $0.4-0.8 \% \mathrm{~S}$, and $k$ indicates the $N_{\mathrm{CCN}}$ increase with S. For the same chemical composition for all particles, $k$ will be higher when the concentration of smaller CCN with higher critical supersaturations $\left(\mathrm{S}_{\mathrm{c}}\right)$ is relatively greater. Therefore it is understandable that $k$ seems to have a negative relationship with $D_{\mathrm{g}}$ in Fig. 4c. However, $k$ is the highest in December when $D_{\mathrm{g}}$ is not especially small compared to other months. Such high $k$ could be explained if relatively large proportions of the parti- cles measured in December had high $\mathrm{S}_{\mathrm{c}}$ even though the sizes were not small. This would imply relatively low aerosol hygroscopicity in December especially for small particles. Nevertheless, these particles were considered to be more hygroscopic than the particles measured during March and April: note the low $N_{\mathrm{CCN}} / N_{\mathrm{CN}}$ in these two months despite the large $D_{\mathrm{g}}$.

\subsubsection{Diurnal variation}

Diurnal variations were obtained by averaging the data every $30 \mathrm{~min}\left(N_{\mathrm{CN}}, N_{\mathrm{CCN}}\right.$ and $\left.D_{\mathrm{g}}\right)$ or every hour $\left(N_{\mathrm{CCN}} / N_{\mathrm{CN}}\right.$ and $k$ ) of the day. The average numbers of the measurements used to represent each time bin are $897 \pm 7,725 \pm 9$, $715 \pm 9,695 \pm 19$ and $967 \pm 7$ for $N_{\mathrm{CN}}, N_{0.4 \%}, N_{0.6 \%}$, $N_{0.8 \%}$ and $D_{\mathrm{g}}$, respectively. Similarly these numbers are $552 \pm 5,552 \pm 6,549 \pm 7$ and $729 \pm 7$ for $N_{0.4 \%} / N_{\mathrm{CN}}$, $N_{0.6 \%} / N_{\mathrm{CN}}, N_{0.8 \%} / N_{\mathrm{CN}}$ and $k$, respectively. Seasonally classified diurnal variations are shown in Fig. 5. For $N_{\mathrm{CN}}$, there is a clear minimum before dawn and there are midmorning and evening peaks. This diurnal pattern changes little from season to season except that the concentration itself is much higher during winter than the other seasons (Fig. 5a). $N_{\mathrm{CCN}}$ show a different pattern from $N_{\mathrm{CN}}$ : the early morning minimum is inconspicuous or absent, and the midmorning maximum is pronounced only in winter (Fig. 5b). Now we examine the possible reasons for these diurnal patterns.

\section{Traffic amount}

The average diurnal variations of $N_{\mathrm{CN}}, N_{0.6 \%}, N_{0.6 \%} / N_{\mathrm{CN}}$, $D_{\mathrm{g}}$ and $k$ for the entire period are shown in Fig. 6 along with the hourly averaged motor vehicle traffic amounts on the major road just outside the Yonsei University campus $(\sim 300 \mathrm{~m}$ from the measurement site). Motor vehicle traffic data are limited to only 25 days, mostly during autumn, but the traffic trend is expected not to differ significantly with the seasons. It is reported that in Seoul 30 and $70 \%$ of motor vehicles on the road use diesel and gasoline as their fuel, respectively, (Pandey et al., 2008) although it should be noted that diesel vehicles are larger and consume more fuel.

The most prominent feature in Fig. 6 is that the time of the minimum $N_{\mathrm{CN}}$ around 04:00-05:00 LT coincides with the traffic minimum. The time of maximum $N_{\mathrm{CN}}$ at 19:00-20:00 LT slightly lags the traffic maximum (18:0019:00 LT). $N_{\mathrm{CN}}$ increases sharply during 05:00-08:00 LT, which is in accordance with the increasing traffic during these hours. Strikingly similar behavior for nitric oxide (NO) has been reported (Pandey et al., 2008). Such similarity suggests that motor vehicles, which are a primary source of NO, are also the main source of $N_{\mathrm{CN}}$ in Seoul. Such similarity is not obvious for $N_{\mathrm{CCN}}$, implying that traffic emissions may not have been the primary source of $N_{\mathrm{CCN}}$. However, $N_{\mathrm{CCN}}$ is not completely independent of traffic emissions. Figure 7 

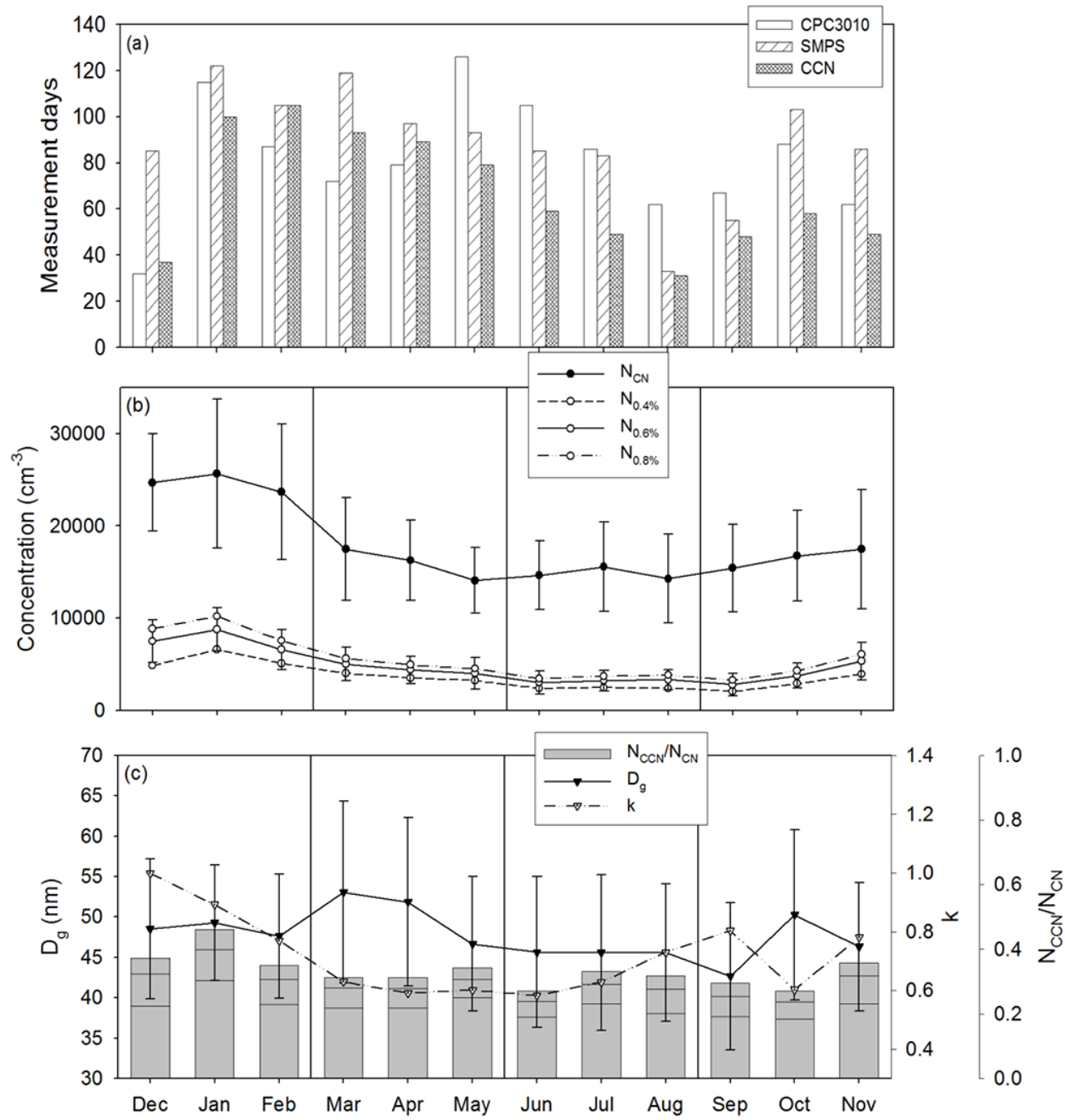

Figure 4. (a) Distribution of measurement days in Seoul for each month of the year between 2004 and 2010; seasonal variations of (b) $N_{\mathrm{CN}}$ and $N_{\mathrm{CCN}}$ and (c) $N_{\mathrm{CCN}} / N_{\mathrm{CN}}, D_{\mathrm{g}}$ and parameter $k$ of the Twomey relationship $\left(\mathrm{N}=\mathrm{C} \times \mathrm{S}^{\mathrm{k}}\right)$ in Seoul. In (b) and (c), the error bars indicate standard deviation for $N_{\mathrm{CN}}, N_{0.6 \%}$ and $D_{\mathrm{g}}$. In (c), the top, middle and bottom lines within each grey box indicate $N_{\mathrm{CCN}} / N_{\mathrm{CN}}$ for $0.4,0.6$ and $0.8 \% \mathrm{~S}$.

shows the relationship between the hourly averaged values of traffic amount and $N_{\mathrm{CCN}}$ and $N_{\mathrm{CN}}$. If we interpret $N_{\mathrm{CN}}$ as $N_{\mathrm{CCN}}$ at a very high $S$ (i.e., $>0.8 \%$ ), we can say that this correlation becomes progressively more significant with increasing S. This implies, then, that the particles originating from traffic emission were more likely to be the particles that could be activated mostly at higher S, probably because they were smaller and less hygroscopic. Hudson (1991) suggested diesel engines as a CCN traffic source.

\section{Planetary boundary layer height}

Planetary boundary layer (PBL) height can have an effect on $N_{\mathrm{CN}}$ and $N_{\mathrm{CCN}}$ because the atmosphere becomes diluted as PBL expands. Due to the lack of the atmospheric thermo- dynamic sounding data with sufficiently high temporal resolution, we instead analyzed the continuous micro pulse lidar (MPL) measurement data obtained at the Seoul National University campus in Seoul (Kim et al., 2007) to estimate PBL height. Seoul National University is located $11 \mathrm{~km}$ south of the Yonsei measurement site. MPL measures the vertical profile of aerosol attenuated backscatter coefficient at $532 \mathrm{~nm}$ wavelength every $15 \mathrm{~min}$. The automated wavelet covariance transform (WCT) method from Brooks (2003) was applied to the backscatter profiles obtained from August 2006 to December 2010. Only the days when there was no precipitation and the daily cloud amount was less than $1 / 10$ were selected; 213 days (mostly during winter) met those criteria during the above period.

For these selected days, the average diurnal variation of PBL height shows almost no seasonal variation although 

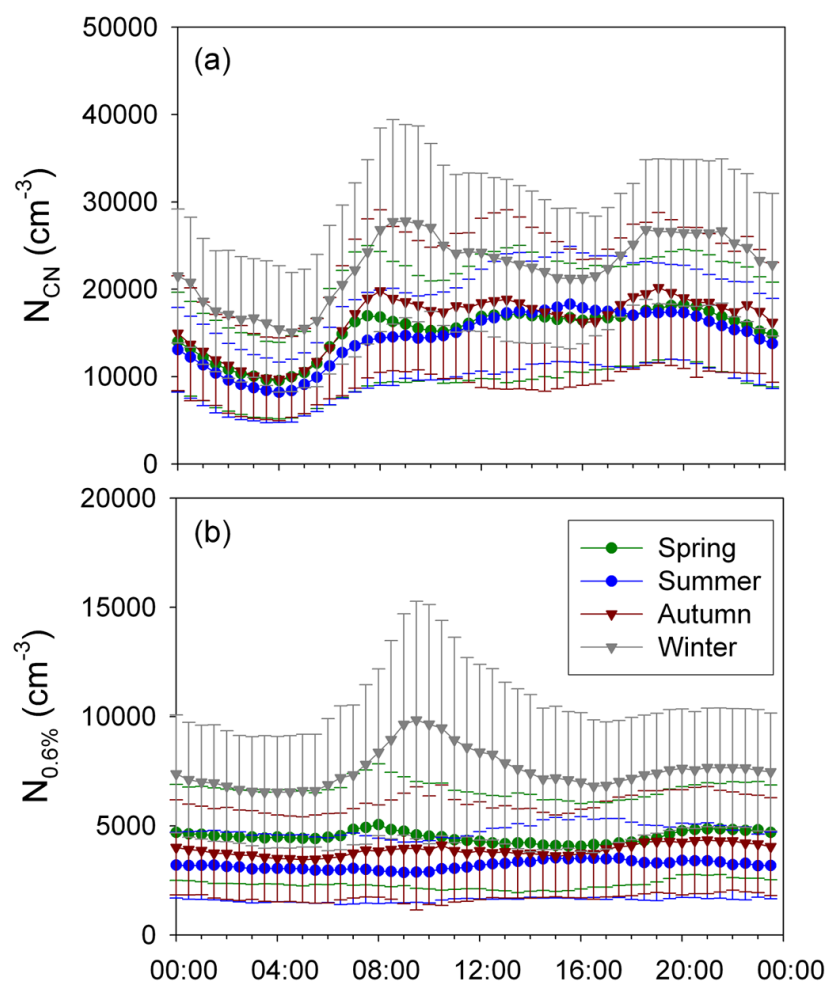

Figure 5. Average diurnal variation of (a) $N_{\mathrm{CN}}$ and (b) $N_{0.6 \%}$ in Seoul for each season. The time is local standard time and no daylight saving time was observed.

the maximum PBL height of the day differs from season to season: about $1500 \mathrm{~m}$ during summer and lower than $1000 \mathrm{~m}$ during winter (not shown). Generally PBL starts to rise around 09:00 LT, reaches a maximum at about 16:00 LT, lowers to $600-800 \mathrm{~m}$ at about midnight and stays largely at this height throughout the nighttime. When this night period (00:00-09:00 LT) is excluded there is a remarkably consistent but opposite trend between the PBL height and $N_{0.6 \%}$ as shown in Fig. 8, where the normalized PBL height and $N_{0.6 \%}$ are shown together with the axis for the normalized PBL height reversed. The normalization is done for each day by converting the daily maximum and minimum values of $N_{0.6 \%}$ to 1.0 and 0.0 , respectively, and converting the other values in between proportionally. Normalized PBL height is similarly obtained. In this way the influence of daily fluctuations is removed for both parameters. However, the days when both parameters were simultaneously measured for almost an entire day (more than $18 \mathrm{~h}$ ) were limited (40 days) and they were usually not consecutive. Along with the normalization process itself, this is the main reason why the values just before and after midnight are not smoothly varied especially for normalized $N_{0.6 \%}$ in Fig. 8 .

Figure 9 shows the scatterplot of the hourly averaged PBL height vs. $N_{\mathrm{CCN}}$ and $N_{\mathrm{CN}}$ in a manner similar to Fig. 7. Note that $N_{\mathrm{CN}}$ and $N_{\mathrm{CCN}}$ in Fig. 9 are higher than the correspond-

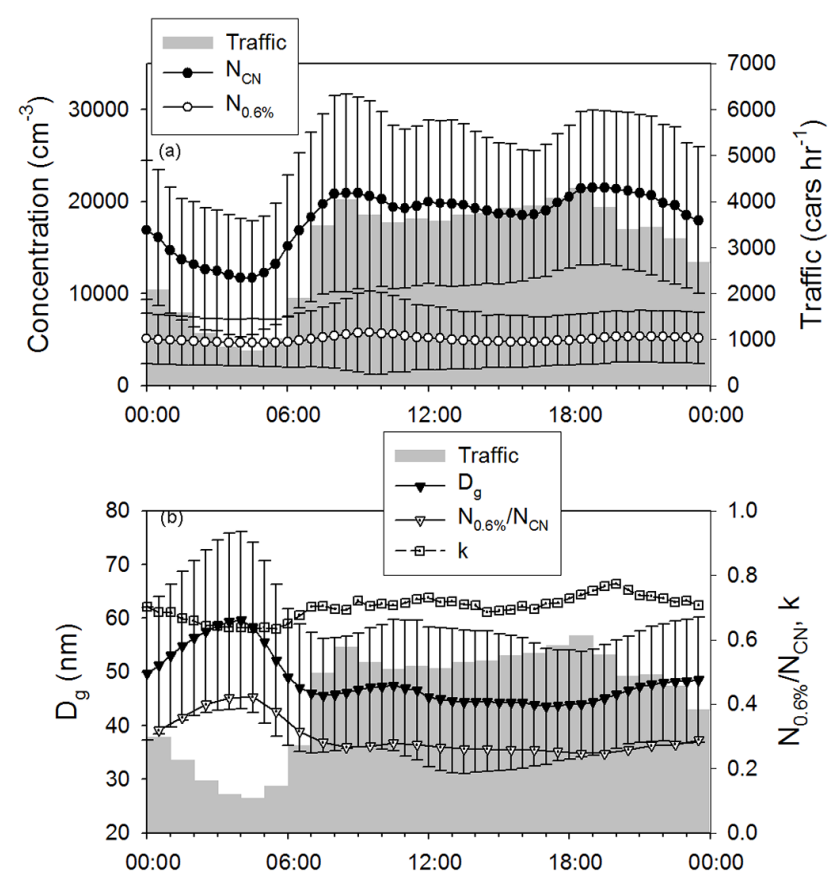

Figure 6. Average diurnal variation of (top) $N_{\mathrm{CN}}, N_{0.6 \%}$ and traffic amount on the nearest major road and (bottom) $D_{\mathrm{g}}, N_{0.6 \%} / N_{\mathrm{CN}}$ and $\mathrm{k}$ in Seoul. Traffic amount is replotted with the same vertical scale at the bottom panel. Error bars indicate standard deviation.

ing values in Fig. 7 because in Fig. 9 mostly data from winter are used to calculate $N_{\mathrm{CN}}$ and $N_{\mathrm{CCN}}$ to match the times of MPL data, while the data used in Fig. 7 are mostly from autumn as mentioned in the previous section. The data points for 09:00-24:00 are highlighted with a circle in Fig. 9, and, as expected from Fig. $8, N_{\mathrm{CCN}}$ for all $S$ show strong negative correlations with the PBL height. However, no such tendency is found for $N_{\mathrm{CN}}$ (panel d). These contrasting results seem to be related to the diurnal variation of traffic amount and its much closer relationship with $N_{\mathrm{CN}}$ than with $N_{\mathrm{CCN}}$. For $N_{\mathrm{CN}}$ the increased traffic amount that nearly reaches its daily maximum at 09:00 LT can compensate for the dilution effect of PBL height which starts to increase at this hour (Fig. 8). After 16:00 LT, the PBL height starts to decrease but the traffic amount starts to decrease as well a few hours later (18:00 LT) and therefore the concentrating effect of descending PBL height is again compensated by decreasing traffic. Because traffic emission has only a secondary influence on $N_{\mathrm{CCN}}$, such compensations do not seem to occur and the effect of dilution and concentration due to PBL height variation is fully exerted for $N_{\mathrm{CCN}}$. From midnight to 09:00 LT, PBL height shows little variation, and therefore the traffic emission seems to act as the single most important factor driving both $N_{\mathrm{CN}}$ and $N_{\mathrm{CCN}}$. 

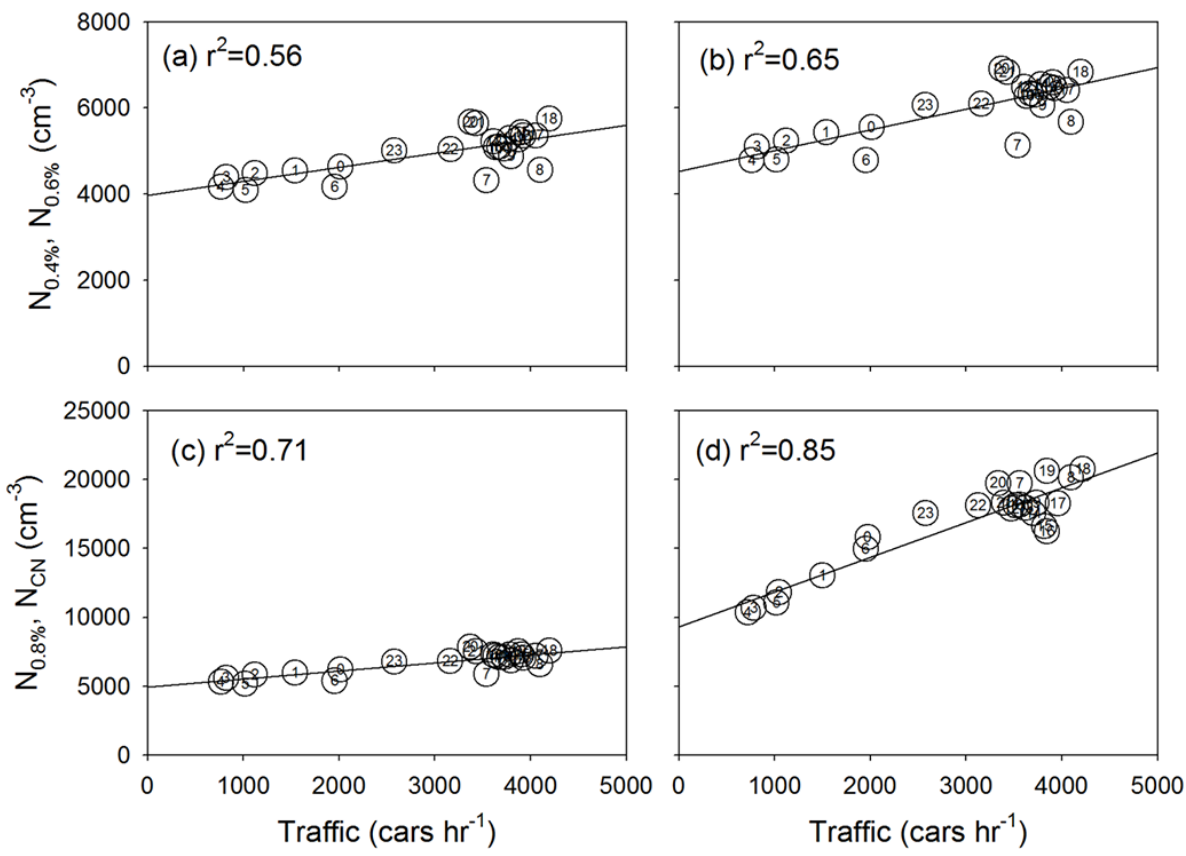

Figure 7. Scatterplot of traffic amount vs. $N_{\mathrm{CCN}}$ at (a) $0.4 \% \mathrm{~S}$, (b) $0.6 \% \mathrm{~S}$ and (c) $0.8 \% \mathrm{~S}$, and (d) $N_{\mathrm{CN}}$ in Seoul. The numbers inside the symbols indicate the hour of the day. Note the different ordinate scales in the upper and lower panels.

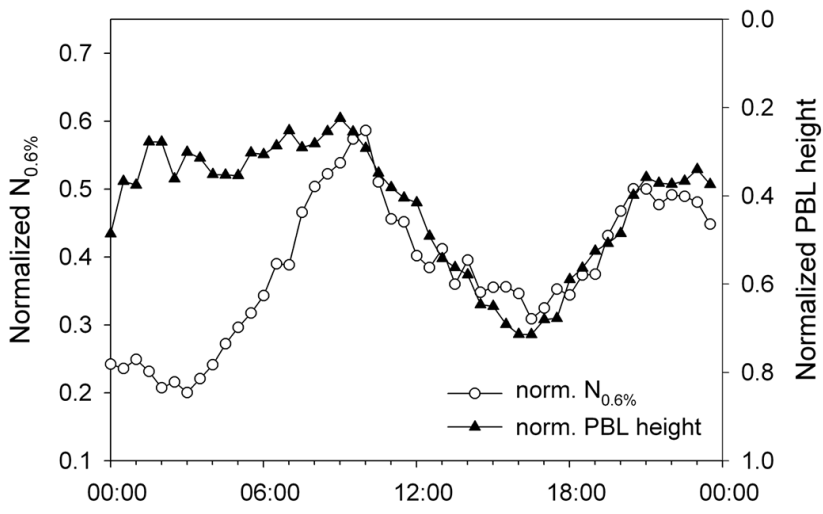

Figure 8. Average diurnal variation of normalized $N_{0.6 \%}$ and normalized PBL height calculated from MPL data measured on clear days in Seoul. Both vertical axes are scaled to illustrate the diurnal variation, and the axis for normalized PBL height is reversed for illustration.

\section{Airborne measurement $(2009,2011)$}

\subsection{Instrumentation}

Two aircraft campaigns were conducted using a Beechcraft King Air (C90GT) aircraft. The first was conducted from 30 September to 18 October 2009 and the second from 8 to 17 June 2011. For both campaigns, a DMT CCNC and a TSI CPC 3010 were used to measure $N_{\mathrm{CCN}}$ and $N_{\mathrm{CN}}$. For the 2011 campaign, a TSI Nephelometer 3536 was also onboard the aircraft and measured scattering coefficients at three wavelengths: 450,500 and $700 \mathrm{~nm}$. All instruments were calibrated before each campaign. Because the internal $S$ field within the $\mathrm{CCNC}$ varies with ambient pressure (Roberts and Nenes, 2005), CCNC was operated with the fixed internal $S$ of $0.6 \%$ and the fixed internal pressure of 650 and $530 \mathrm{mb}$ for the 2009 and 2011 campaigns, respectively. Such pressure values were selected to guarantee that they were sufficiently lower than the ambient pressures at the maximum flight altitudes of the two campaigns $(3000 \mathrm{~m}$ for 2009 and $5000 \mathrm{~m}$ for 2011). In order to make it possible to offset ambient pressure fluctuations an orifice, an adjustable valve and a pump were used. The counting efficiency of CPC is known to be insensitive to ambient pressure fluctuations under such pressure ranges (Zhang and Liu, 1991). The nephelometer was considered to not suffer from ambient pressure fluctuations (Bodhaine et al., 1991).

During the 2009 campaign, an isokinetic inlet system was not available and the aircraft cabin window was slightly open in order to extend a quarter inch tube and draw sample air from outside the aircraft. In order to see the effect of such an anisokinetic inlet design, an additional TSI CPC 3010 was installed on the Korea Global Atmosphere Watch Center (KGAWC, $36.5^{\circ} \mathrm{N}, 126.3^{\circ} \mathrm{E}$ ), which is about $7 \mathrm{~km}$ from Tae-An Airport $\left(36.6^{\circ} \mathrm{N}, 126.3^{\circ} \mathrm{E}\right)$, where the aircraft took off and landed. It is found that $N_{\mathrm{CN}}$ measured during takeoffs and landings (altitude $<400 \mathrm{~m}$ ) exhibited values 21 $55 \%$ larger than $N_{\mathrm{CN}}$ measured at KGAWC. Such values can be interpreted to represent error arising from an anisokinetic inlet. During the 2011 campaign, an isokinetic inlet system was implemented. 

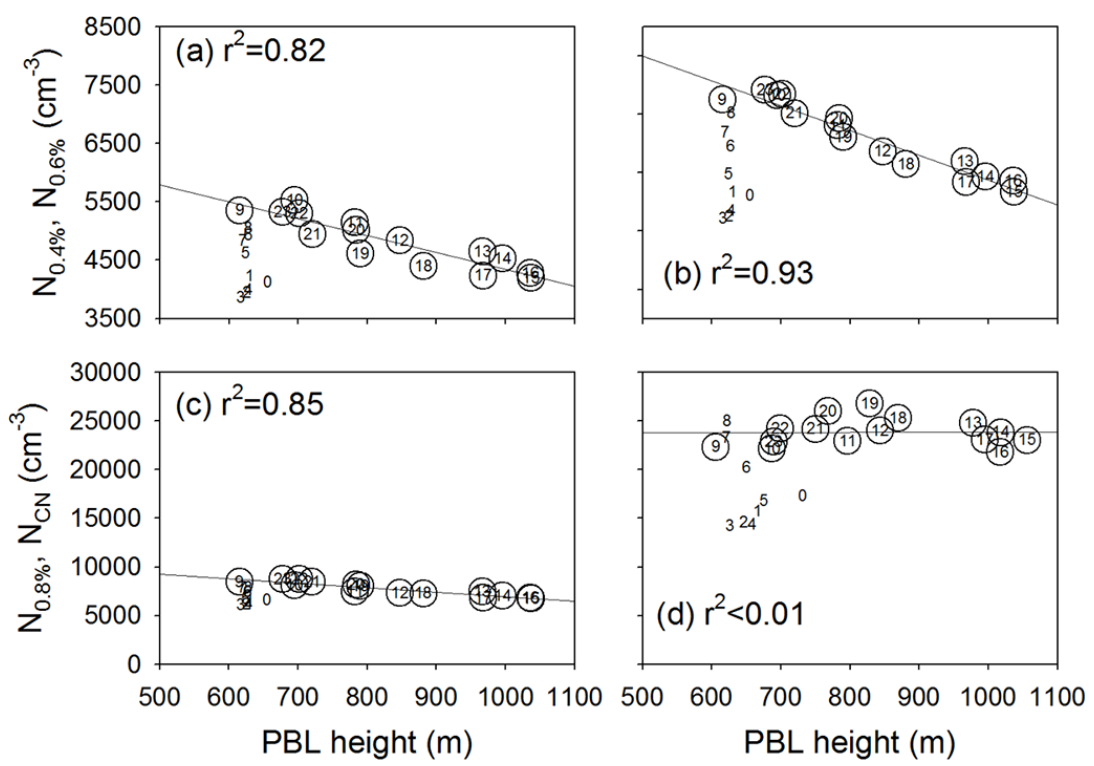

Figure 9. Scatterplot of PBL height vs. $N_{\mathrm{CCN}}$ at (a) $0.4 \% \mathrm{~S}$, (b) $0.6 \% \mathrm{~S}$ and (c) $0.8 \% \mathrm{~S}$, and (d) $N_{\mathrm{CN}}$ in Seoul. The numbers are the hour of the day, and the hours between 09:00 LT and midnight are circled to illustrate the relationship. The linear regression line and the coefficient of determination are calculated only for these hours.

\subsection{Flight design}

Measurement data were obtained from eight research flights of 2009 campaign. The flight design was aimed at verifying east-west gradients of $N_{\mathrm{CN}}$ and $N_{\mathrm{CCN}}$ as explained in Sect. 1. The aircraft took off at Tae-An Airport located on the west coast of the Korean Peninsula and then chose one of two routes. For the first route, it flew west to $124.7^{\circ} \mathrm{E}$ over the Yellow Sea, then headed south at constant longitude until $33.4^{\circ} \mathrm{N}$, then it flew east to Jeju Island $\left(126.3^{\circ} \mathrm{E}\right)$ and headed back to Tae-An Airport. This closed-circuit route is denoted as the "Yellow Sea route". In some flights, the circuit route in exactly the opposite direction was chosen. The second route consisted of flying east across the Korean Peninsula and over the East Sea to $131.15^{\circ} \mathrm{E}$, then heading straight north to Ulleung Island $\left(37.5^{\circ} \mathrm{N}, 130.9^{\circ} \mathrm{E}\right)$ and then returning to Tae-An; this is the "East Sea route". The two routes are shown in Fig. 10. During most of the flights the aircraft cruised at $3000 \mathrm{~m}$ altitude, but it made vertical soundings on each leg, spiraling down to about $500 \mathrm{~m}$ and back up to the cruising altitude. The horizontal area span during the spiral was smaller than $9 \times 10 \mathrm{~km}$.

During the 2011 campaign, data were obtained from three research flights. The first and second flights took the Yellow Sea route and the East Sea route, respectively. The last flight covered both the Yellow Sea and the East Sea. The vertical soundings were made in an identical manner to that of the 2009 campaign but their maximum altitude was extended to $5000 \mathrm{~m}$.

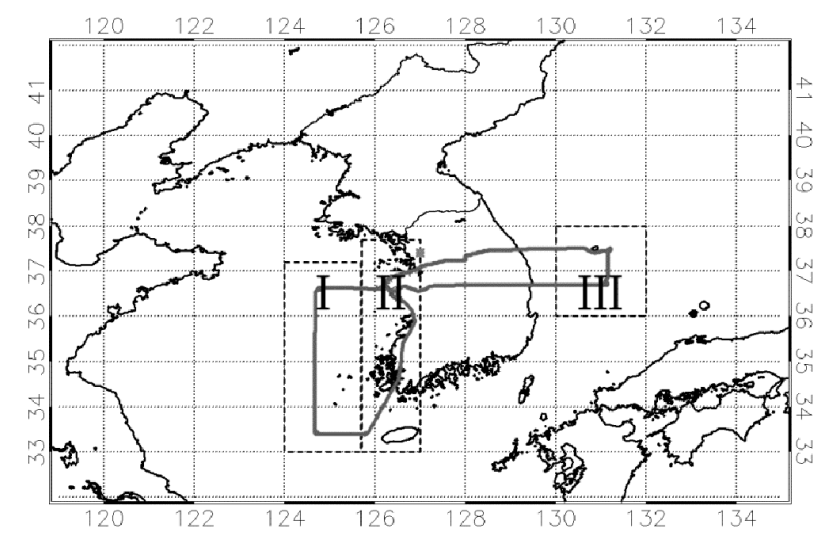

Figure 10. Classification of regions where vertical measurements took place during the 2009 and 2011 campaigns. I: the Yellow Sea; II: west coast of the Korean Peninsula; and III: the East Sea. Two grey loops represent the Yellow Sea route (includes I and II) and the East Sea route (II and III). The grey square near the upper right corner of region II designates the location of Seoul. The main airport is located at the junction point of the two cruise routes, near II.

\subsection{Results}

\subsubsection{Vertical distribution}

In total, 17 and 11 vertical soundings were made during the 2009 and 2011 campaigns, respectively. For comparison, the vertical soundings are classified into three regions based on longitude as shown in Fig. 10: region I $\left(33-37^{\circ} \mathrm{N} \times 124\right.$ $\left.125.7^{\circ} \mathrm{E}\right)$ covers the eastern part of the Yellow Sea, region II 

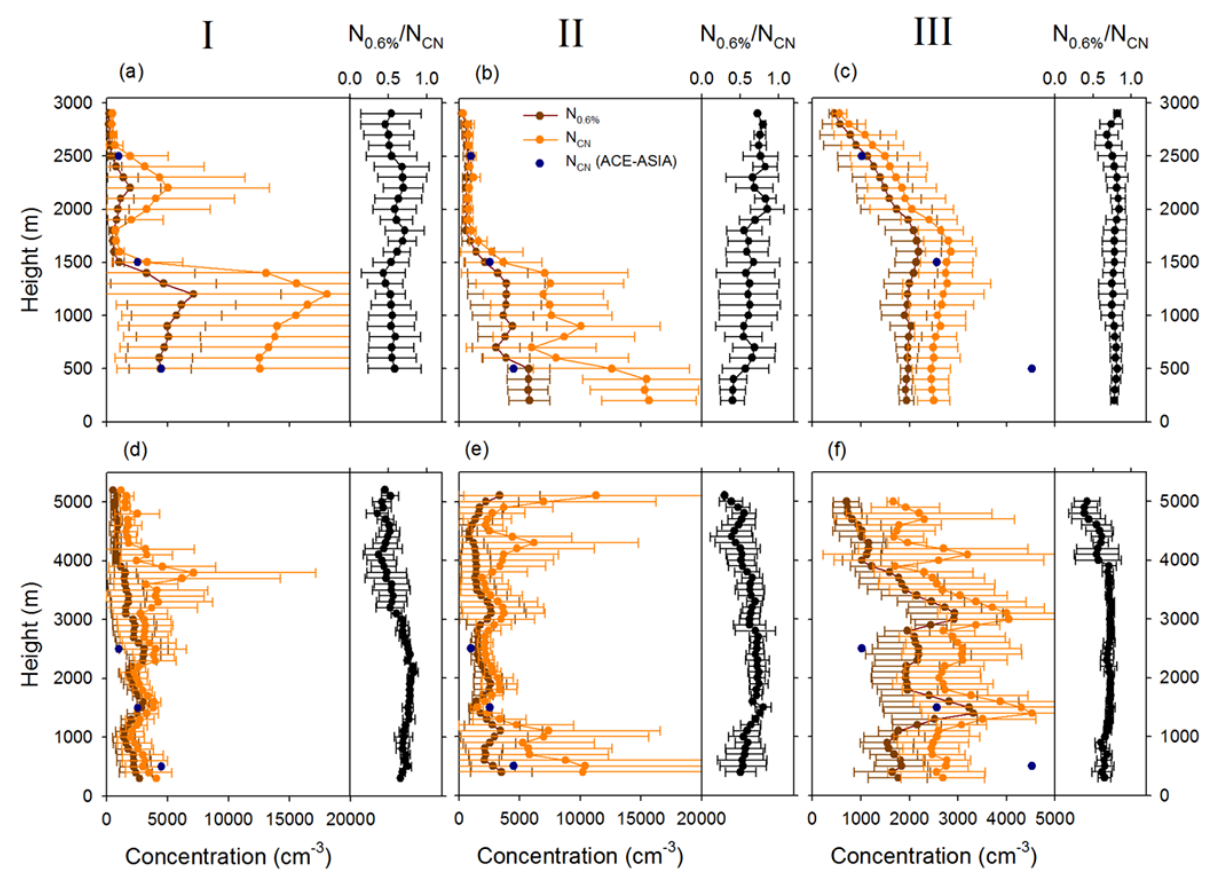

Figure 11. Average vertical distributions of $N_{0.6 \%}$ (brown), $N_{\mathrm{CN}}$ (orange) and $N_{0.6 \%} / N_{\mathrm{CN}}$ (black) during the 2009 (a, b, c) and 2011 (d, e, f) campaigns, for each classified region (I, II and III). The averages are taken for each $100 \mathrm{~m}$ height bin. Note that the scale of the $y$ axis is different for the two campaigns. $N_{\mathrm{CN}}$ measured during ACE-ASIA (Clarke and Kapustin, 2010) are marked with blue dots for comparison. Error bars denote standard deviations.

$\left(33-37.7^{\circ} \mathrm{N} \times 125.7-127^{\circ} \mathrm{E}\right)$ covers the western coast of the Korean Peninsula and region III $\left(36-38^{\circ} \mathrm{N} \times 130-132^{\circ} \mathrm{E}\right)$ covers the East Sea around Ulleung Island. Regions I and II are used to see whether the effects of local sources in the western part of the Korean Peninsula can be separated from the overall influence of continental outflow. A total of 4,5 and 8 soundings were made in regions I, II and III, respectively, during the 2009 campaign, and 4, 3 and 4 soundings during the 2011 campaign.

\section{$N_{\mathrm{CN}}$ and $N_{0.6 \%}$}

Figure 11 shows the average vertical distributions of $N_{0.6 \%}$, $N_{\mathrm{CN}}$ and $N_{0.6 \%} / N_{\mathrm{CN}}$ for each region from the two campaigns. (All of the data shown in this study is adjusted to a surface pressure of $1000 \mathrm{mb}$.) First, the data are averaged by $100 \mathrm{~m}$ altitude bins for each spiral sounding. These $100 \mathrm{~m}$ altitude bin average values are then averaged for each region. In most of the panels in Fig. 11, $N_{\mathrm{CN}}$ is relatively higher at lower altitudes, showing the influence of surface sources. $N_{0.6 \%}$ also shows a similar trend but with smaller vertical gradients, implying that the influence of the surface sources is less pronounced for CCN. On the other hand, $N_{0.6 \%} / N_{\mathrm{CN}}$ does not vary much with altitude and the average for the whole depth of each sounding ranges from 0.57 to 0.78 in Fig. 11. Average $N_{\mathrm{CN}}$ is comparable to $N_{\mathrm{CN}}$ obtained at locations between the Korean Peninsula and Japan during Asian Pacific Regional Aerosol Characterization Experiments (ACE-Asia) in 2001 (Clarke and Kapustin, 2010) as marked in Fig. 11. It is also worth noting that when the layer with enhanced particle concentration (such as the noticeable bumps observed around $3000 \mathrm{~m}$ altitude in panels e and f) is not considered, $N_{\mathrm{CN}}$ and $N_{0.6 \%}$ measured near or above $3000 \mathrm{~m}$ altitude were comparable to those measured during ACE-1 in 1995 over the Southern Ocean when the air mass originated from the Australian continent (Hudson et al., 1998). Based on measurements of $N_{\mathrm{CN}}$ and $N_{\mathrm{CCN}}$ at $0.3 \% \mathrm{~S}$ in a southwestern island of Japan, Adhikari et al. (2005) suggested that $N_{\mathrm{CCN}} / N_{\mathrm{CN}}$ of 0.5 or higher was characteristic of continentally/anthropogenically influenced marine air. Consequently, we may conclude that our values also mostly represent such air masses in East Asia. However, these values are still about a factor of two larger than those in Seoul (discussed above), suggesting greater $N_{\mathrm{CCN}} / N_{\mathrm{CN}}$ over this marine region than in a highly populated city.

For both the 2009 and the 2011 campaign, but especially for the 2009 campaign, $N_{0.6 \%}$ and $N_{\mathrm{CN}}$ below $1000 \mathrm{~m}$ altitude are higher over regions I and II than over region III (Fig. 11), surely due to the fact that regions I and II are closer to China and that local industrial activities are also more widespread in western Korea. However, there is no significant difference between regions I and II, except somewhat higher concentrations for region II, perhaps due to the addition of local sources. The general westward gradient 


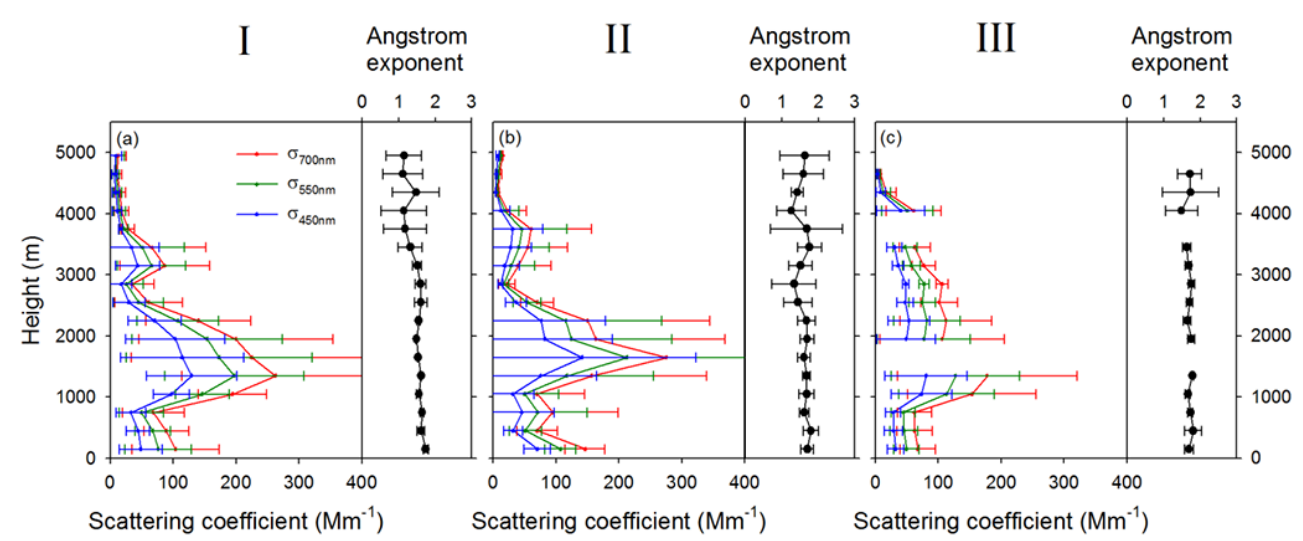

Figure 12. Average vertical distributions of aerosol scattering coefficient $(\sigma)$ at 450 (blue), 550 (green) and 700 (red) nm wavelengths during the 2011 campaign for the regions (a) I, (b) II and (c) III, respectively. Corresponding distributions of the Angström exponent are also shown in each panel.

diminishes at higher altitudes, indicating that the influences of the surface sources are more likely to be confined to the PBL. Much smaller standard deviations of $N_{0.6 \%} / N_{\mathrm{CN}}$ over region III at the lowest altitudes suggest that there are fewer local sources or particle formation events over this region than over regions I and II.

The relatively large standard deviations as well as the high values of $N_{\mathrm{CN}}$ shown in several panels of Fig. 11 (e.g., near the surface in a, b and e; between $2300 \mathrm{~m}$ and $4000 \mathrm{~m}$ altitudes in d) are suspected to be due to occasional particle formation and growth events that led to elevated $N_{\mathrm{CN}}$ in the affected region. More detailed discussion on this is given below.

\section{Relationship with the scattering coefficient}

Vertical distributions of the $300 \mathrm{~m}$ altitude bin averaged scattering coefficient $(\sigma)$ at three wavelengths $(450,550$ and $700 \mathrm{~nm}$ ) and the Angström exponent (AE) measured during the 2011 campaign are shown in Fig. 12 for each of the regions I, II and III. $\sigma$ values tend to be higher on the western side of the Korean Peninsula than on the eastern side. The $\sigma$ for $550 \mathrm{~nm}\left(\sigma_{550}\right)$ of $50-110 \mathrm{Mm}^{-1}$ below $1000 \mathrm{~m}$ altitude is a factor of two to four smaller than $\sigma_{550}$ measured in Seoul ( $\sim 200 \mathrm{Mm}^{-1}$; Shim et al., 2008) but similar to or larger than $\sigma_{550}$ observed over the East Asian seas during the ACE-ASIA project (Carrico et al., 2003). In Fig. 12 there is an elevated $\sigma$ layer between 1000 and $2500 \mathrm{~m}$ altitude for all three regions, and then it decreases with altitude to near the detection limit above $4000 \mathrm{~m}$ altitude. This trend is not very consistent with the vertical profiles of $N_{\mathrm{CN}}$ and $N_{0.6 \%}$ shown in Fig. 11d-f except for the rather similar feature in region III (compare Fig. 11f and Fig. 12c). This demonstrates that the particle number concentration is not the only parameter that determines the scattering properties.
However, some previous measurement studies over the Korean Peninsula (Shim et al., 2008; Kim et al., 2012) and in other parts of the globe (Andreae, 2009; Clarke and Kapustin, 2010) suggest a positive correlation between $\sigma$ and $N_{\mathrm{CN}}$ and between $\sigma$ and $N_{0.6 \%}$. Figure 13 is the scatterplot of simultaneously measured $N_{\mathrm{CN}}$ and $N_{0.6 \%}$ vs. $\sigma_{550}$ for the entire 2011 campaign, which indicates a positive correlation with scatter. $\sigma_{550}$ tends to be smaller at higher altitudes regardless of $N_{\mathrm{CN}}$ and $N_{0.6 \%}$ variations. Throughout the entire campaign, $\mathrm{CN}$ and $\mathrm{CCN}(0.6 \%)$ observed at the highest altitudes (> $4500 \mathrm{~m}$, purple) tend to scatter less light: all 357 data points collected above $4500 \mathrm{~m}$ altitude are located below the dashed line for $\mathrm{CN}$ and $\mathrm{CCN}(0.6 \%)$ in Fig. 13. In particular, over region II, $N_{\mathrm{CN}}$ and $N_{0.6 \%}$ increase above $4900 \mathrm{~m}$ altitude (Fig. 11e), but the increase here for $\sigma$ is negligible (Fig. 12b). A careful examination of the nephelometer data found no instrumental issue for this case, implying that these $\mathrm{CN}$ and $\mathrm{CCN}(0.6 \%)$ indeed had negligible $\sigma$. In relation to this unique feature, it is worth mentioning that at higher altitudes $N_{0.6 \%} / N_{\mathrm{CN}}$ tended to decrease with altitude for all three regions during the 2011 campaign (Fig. 11d-f). This may suggest that aerosol particles were smaller at higher altitudes and therefore $\sigma_{550}$ was smaller. However, this cannot completely explain the complicated correspondence between $\sigma_{550}$ and $N_{\mathrm{CN}}$ or $N_{0.6 \%}$ shown in Fig. 13, which reflects the fact that the relationship between number concentration and scattering coefficient of the particles is mediated by various properties. A detailed analysis of the factors that regulate the relationship between $N_{\mathrm{CN}}, N_{\mathrm{CCN}}$ and $\sigma$ requires further study.

\subsubsection{Horizontal distribution at $3000 \mathrm{~m}$ altitude}

Horizontal distributions of $N_{\mathrm{CN}}$ and $N_{0.6 \%}$ were obtained when the aircraft was cruising at $3000 \mathrm{~m}$ altitude during periods between spiral vertical soundings. The spatial distribution of $N_{0.6 \%}$ is illustrated in Fig. 14. Overall average values 


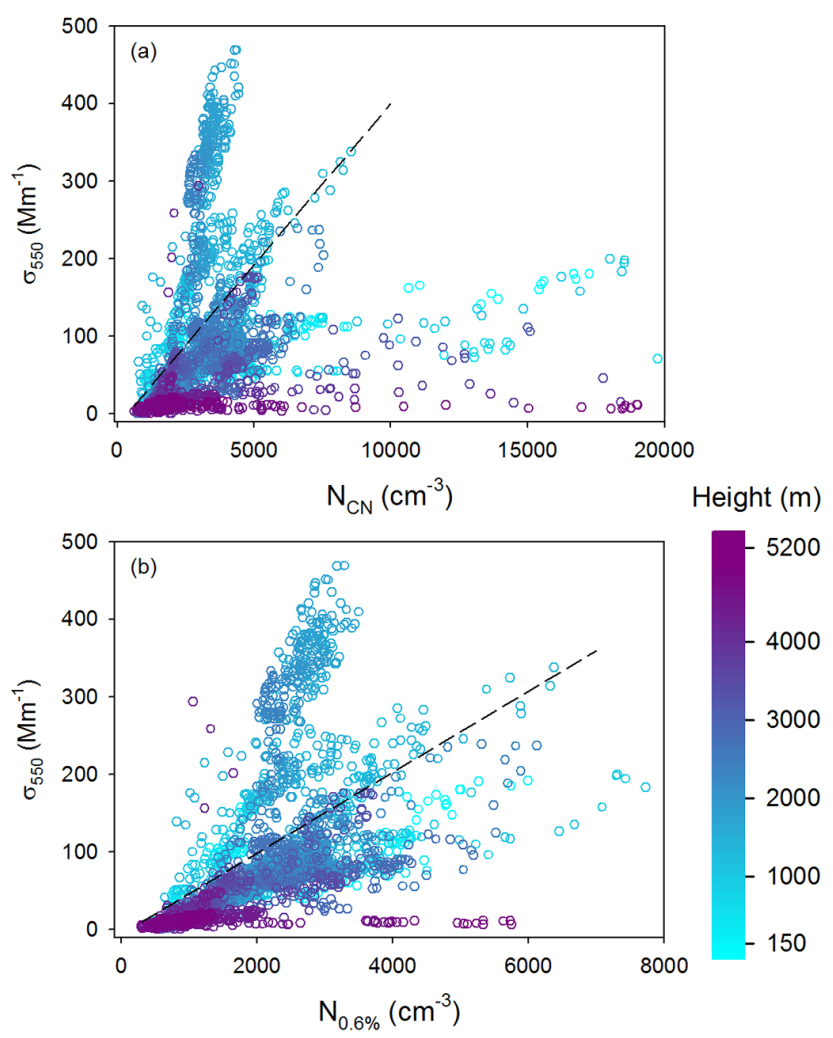

Figure 13. Scatterplot of simultaneously measured (a) $N_{\mathrm{CN}}$ vs. $\sigma_{550}$, and (b) $N_{0.6 \%}$ vs. $\sigma_{550}$. The color of each data represents the altitude of measurement. The dashed lines are not regressions but drawn for explanatory purposes for each panel (see text).

of $N_{0.6 \%}, N_{\mathrm{CN}}$ and $N_{0.6 \%} / N_{\mathrm{CN}}$ were $1207 \pm 915 \mathrm{~cm}^{-3}$, $1870 \pm 1463 \mathrm{~cm}^{-3}$ and $0.64 \pm 0.06$, respectively. Average values of $\sigma$ for 450,550 and $700 \mathrm{~nm}$ and $\mathrm{AE}$ measured during the 2011 campaign were $57.0 \pm 42.7 \mathrm{Mm}^{-1}$, $42.7 \pm 31.9 \mathrm{Mm}^{-1}, 28.2 \pm 21.1 \mathrm{Mm}^{-1}$ and $1.51 \pm 0.30$, respectively. Average values for each flight and each campaign are shown in Tables 1 and 2.

Most values of $N_{\mathrm{CN}}$ and $N_{0.6 \%}$ in Table 1 are much lower than values measured within the PBL around the Korean Peninsula (Sect. 4.2), indicating that aerosol characteristics in the free troposphere are certainly different from those within the boundary layer. However, some high values were observed on some days (10 October 2009, 11 and 12 June 2011), which are comparable to or even higher than those measured at the surface sites. $N_{\mathrm{CN}}$ and $N_{0.6 \%}$ higher than $7000 \mathrm{~cm}^{-3}$ and $5000 \mathrm{~cm}^{-3}$, respectively, were also observed during the 15 October 2009 flights on the east coast of the Korean Peninsula (Fig. 14). Such high values may suggest an elevated pollution layer transported from China or local surface emissions reaching high altitudes without much dilution. A westward gradient of $N_{\mathrm{CCN}}$ is apparent only in the flight of 11 October 2009 (Fig. 14), which may indicate that the general westward gradient of aerosol concentrations (Fig. 11) or
AOD (Y.-J. Kim et al., 2011) is mostly confined to the lower atmosphere.

\section{Discussion}

\subsection{Particle formation and growth events}

Buzorius et al. (2004), Lee et al. (2008) and Kim et al. (2009) all independently reported particle formation and growth events observed over the Yellow Sea. Yum et al. (2007) and Kim et al. (2013) also reported such events at Gosan, Jeju Island $\left(33.2^{\circ} \mathrm{N}, 126.1^{\circ} \mathrm{E}\right)$, located south of the Yellow Sea.

Although there was no instrument capable of measuring particle size distribution onboard, such information can be inferred from the $N_{0.6 \%} / N_{\mathrm{CN}}$ data obtained on the aircraft. During the vertical soundings, layers of low $(<0.3)$ $N_{0.6 \%} / N_{\mathrm{CN}}$ compared to those $(\sim 0.6)$ at other altitudes were identified. Small particles generally have high $\mathrm{S}_{\mathrm{c}}$. So the significantly lower value $N_{0.6 \%} / N_{\mathrm{CN}}$ may imply that a greater proportion of the particles are too small to have $S_{c}$ of $0.6 \%$. Such phenomena occurred 16 times during the vertical soundings. Yet one cannot rule out the possibility that such low $(<0.3) N_{0.6 \%} / N_{\mathrm{CN}}$ value may be due to the presence of large particles that have low hygroscopicity. Moreover, the fact that there existed small particles may not alone be sufficient to regard such phenomena as particle formation and growth events.

Now we analyze aerosol size distributions measured with an SMPS at KGAWC located on the west coast of Korea. For all three low $N_{0.6 \%} / N_{\mathrm{CN}}$ events that took place over regions I and II below $1000 \mathrm{~m}$ altitude, an enhanced nucleation mode is found from the SMPS measurement at KGAWC, confirming that a particle formation and growth event had occurred. Conversely, on the days when low $N_{0.6 \%} / N_{\mathrm{CN}}$ event was not observed, particle formation was not observed at KGAWC. Such correspondence strongly supports our claim that low $N_{0.6 \%} / N_{\mathrm{CN}}$ event is a sign of a particle formation and growth event.

The 18 October 2009 research flight conducted between 12:14 and 15:10 local time along the Yellow Sea route provides a unique opportunity to demonstrate the spatial scale of the particle formation and growth event that occurred over the Yellow Sea on this day. Low $N_{0.6 \%} / N_{\mathrm{CN}}$ values at the altitudes below $1000 \mathrm{~m}$ are observed in all three spiral vertical soundings (Fig. 15b) (also during takeoff and landing). Both SMPS measurements at KGAWC and Gosan $\left(33.2^{\circ} \mathrm{N}\right.$, $126.1^{\circ} \mathrm{E}$ ) indicate a particle formation and growth event during this flight (Fig. 15c and d, respectively). This was a very sunny day. The 3-day HYbrid Single Particle Lagrangian Integrated Trajectory model (HYSPLIT) back-trajectories at $500 \mathrm{~m}$ altitude (Draxler and Rolph, 2013; Rolph, 2013) for the three sounding locations and Tae-An Airport consistently indicate that the air mass originated from a remote continental region, suggesting that this region is under the influence 


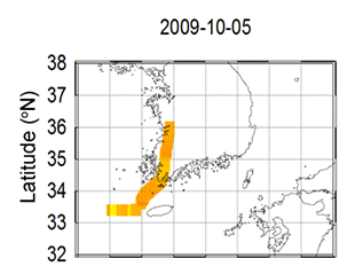

2009-10-11

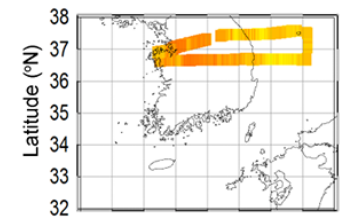

2011-06-08

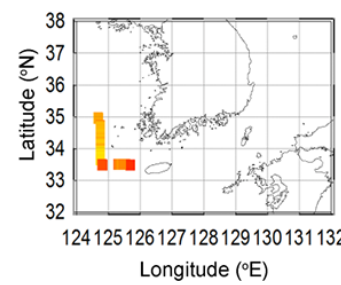

2009-10-06 \#1

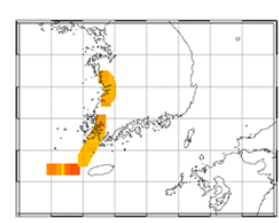

2009-10-12

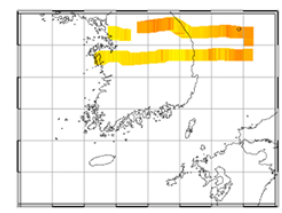

2011-06-11

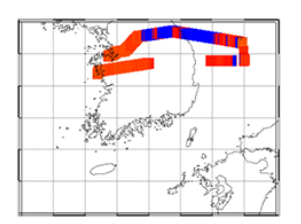

12412512612712812913013113

Longitude $\left({ }^{\circ} \mathrm{E}\right)$

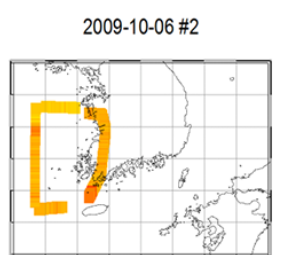

2009-10-15

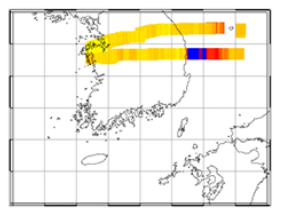

2011-06-12

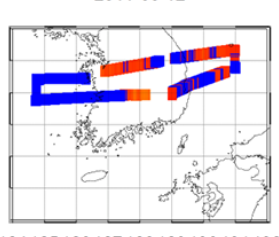

Longitude $\left({ }^{\circ} \mathrm{E}\right)$

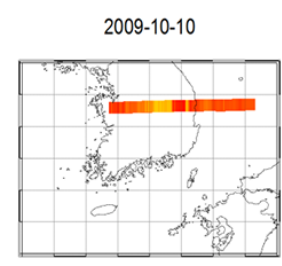

2009-10-18

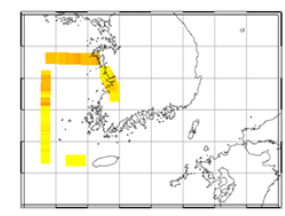

$\mathrm{N}_{0.6 \%}\left(\mathrm{~cm}^{-3}\right)$

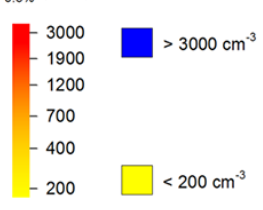

Figure 14. Horizontal distributions of $N_{0.6 \%}$ for all flights. $N_{0.6} \%$ below $200 \mathrm{~cm}^{-3}$ and above $3000 \mathrm{~cm}^{-3}$ are denoted by yellow and blue, respectively. $N_{0.6 \%}$ in between are denoted by the color spectrum from yellow to red as shown at the bottom right.

Table 1. Average $N_{0.6 \%}, N_{\mathrm{CN}}, N_{0.6 \%} / N_{\mathrm{CN}}$ and the data count obtained during the horizontal cruises on each flight of the 2009 and 2011 campaigns.

\begin{tabular}{llrrrr}
\hline Year & Date & $\begin{array}{r}N_{0.6 \%} \\
\left(\mathrm{~cm}^{-3}\right)\end{array}$ & $\begin{array}{r}N_{\mathrm{CN}} \\
\left(\mathrm{cm}^{-3}\right)\end{array}$ & $\begin{array}{r}N_{0.6 \%} / \\
N_{\mathrm{CN}}\end{array}$ & $\begin{array}{r}\text { Data } \\
\text { counts }\end{array}$ \\
\hline 2009 & 5 Oct & $469 \pm 95$ & $876 \pm 376$ & $0.61 \pm 0.17$ & 206 \\
& 6 Oct morning & $515 \pm 130$ & $791 \pm 280$ & $0.68 \pm 0.17$ & 231 \\
& 6 Oct afternoon & $494 \pm 148$ & $647 \pm 198$ & $0.77 \pm 0.10$ & 371 \\
& 10 Oct & $1207 \pm 506$ & $1392 \pm 504$ & $0.85 \pm 0.12$ & 1240 \\
& 11 Oct & $459 \pm 171$ & $632 \pm 287$ & $0.74 \pm 0.13$ & 3164 \\
& 12 Oct & $397 \pm 144$ & $648 \pm 768$ & $0.69 \pm 0.15$ & 2477 \\
& 15 Oct & $641 \pm 918$ & $1186 \pm 1450$ & $0.55 \pm 0.14$ & 2612 \\
& 18 Oct & $292 \pm 119$ & $517 \pm 121$ & $0.58 \pm 0.21$ & 1819 \\
\hline \multirow{2}{*}{2011} & 2009 Average & $559 \pm 280$ & $835 \pm 304$ & $0.68 \pm 0.10$ & \\
\hline 11 Jun & $441 \pm 164$ & $851 \pm 249$ & $0.51 \pm 0.06$ & 1219 \\
& 12 Jun & $2304 \pm 864$ & $3886 \pm 1078$ & $0.59 \pm 0.10$ & 5856 \\
& 2011 Average & $1854 \pm 1250$ & $2904 \pm 1779$ & $0.60 \pm 0.09$ & \\
\hline
\end{tabular}

of an identical air mass (Fig. 16a). The sunny weather conditions and the remote continental origin of the air mass for this event is consistent with the finding of Yum et al. (2007) that such conditions are favorable for particle formation and growth events that took place at Gosan, Jeju Island.

The composite of the vertical soundings and the surface measurements at KGAWC and Gosan lead us to suggest that the spatial extent of the particle formation and growth event that took place in the boundary layer on 18 October 2009 covers at least $100 \times 450 \mathrm{~km}$ of areal extent over the Yellow Sea (Fig. 15a). Considering that the event lasted more than several hours at KGAWC and Gosan, the affected area may have extended even further toward the upwind region by several hundred kilometers (Yum et al., 2007; Hussein et al., 2009). This argument is in accordance with Buzorius et al. (2004), Yum et al. (2007) and Kim et al. (2009), where the authors independently suggested that the particle formation and growth event in this region was not a local event but 
Table 2. Average scattering coefficients $(\sigma)$ at 450, 550 and $700 \mathrm{~nm}$ wavelengths, Angström exponent (AE) and the number of data count obtained during the horizontal cruises on each flight of the 2011 campaign.

\begin{tabular}{llrrrrr}
\hline Year & Date & $\begin{array}{r}\sigma_{450} \\
\left(\mathrm{Mm}^{-1}\right)\end{array}$ & $\begin{array}{r}\sigma_{550} \\
\left(\mathrm{Mm}^{-1}\right)\end{array}$ & $\begin{array}{r}\sigma_{700} \\
\left(\mathrm{Mm}^{-1}\right)\end{array}$ & AE & $\begin{array}{r}\text { Data } \\
\text { count }\end{array}$ \\
\hline 2011 & 8 Jun 8 & $18.0 \pm 44.3$ & $14.2 \pm 34.1$ & $10.1 \pm 22.6$ & $1.17 \pm 0.90$ & 619 \\
& 11 Jun & $86.5 \pm 36.9$ & $63.3 \pm 27.5$ & $40.1 \pm 17.8$ & $1.75 \pm 0.22$ & 3732 \\
& 12 Jun & $140.0 \pm 65.4$ & $105.5 \pm 53.1$ & $70.7 \pm 40.4$ & $1.61 \pm 0.24$ & 4951 \\
\hline
\end{tabular}

(a)
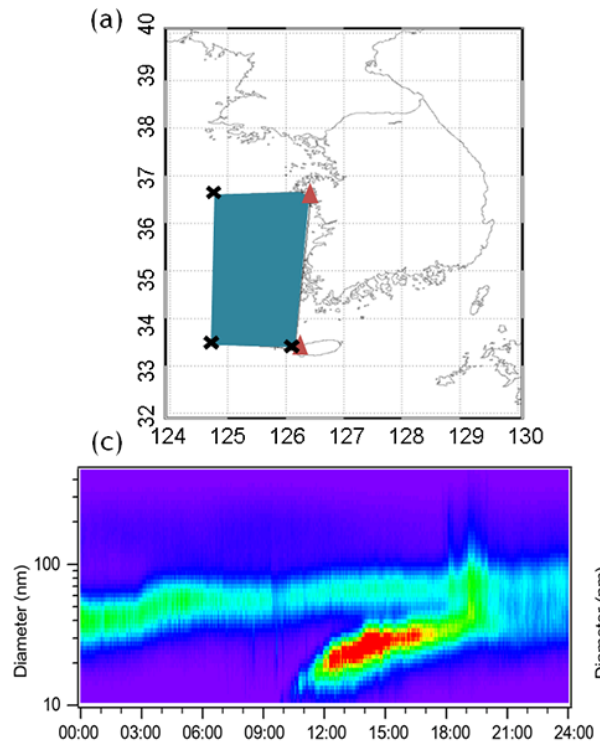

(b)

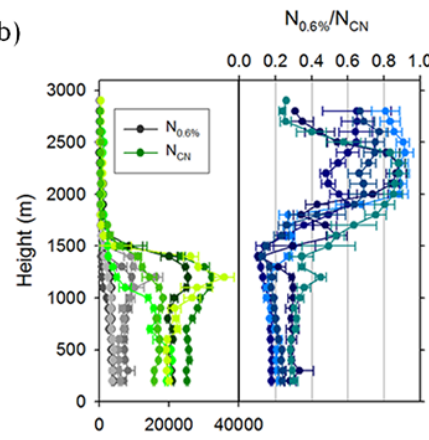

(d) Concentration $\left(\mathrm{cm}^{-3}\right)$

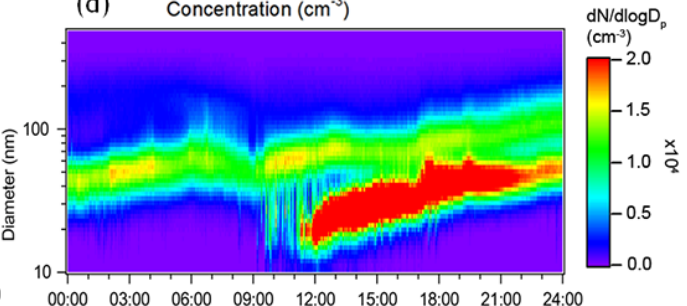

Figure 15. (a) Locations $(\mathrm{X})$ where low $N_{0.6 \%} / N_{\mathrm{CN}}$ was found in the lowest altitude during a flight between 12:14 and 15:30 on 18 October 2009 and the locations (triangle) of the surface SMPS measurements at KGAWC and Gosan; (b) vertical distributions of $N_{\mathrm{CN}}$ (green variant), $N_{0.6 \%}$ (grey variant) and $N_{0.6 \%} / N_{\mathrm{CN}}$ (blue variant) during this flight; and the time variation of aerosol size distributions measured at (c) KGAWC and (d) Gosan on 18 October 2009.

rather took place on a regional scale spanning several hundred kilometers.

On several occasions, low $N_{0.6 \%} / N_{\mathrm{CN}}$ events were observed in a confined layer above $1000 \mathrm{~m}$ altitude, a good example of which is shown in Fig. 17. The 3-day backtrajectories for these occasions also indicated a remote continental origin (Fig. 16b). Although we cannot provide direct evidence (e.g., SMPS measurement data) of particle formation and growth events for such layers, it can be suspected that some kind of secondary particle formation event occurred in the free troposphere or at the entrainment layer, as previously suggested by McNaughton et al. (2004) and Buzorius et al. (2004) for the Yellow Sea region.

\subsection{Composite map of $N_{\mathrm{CN}}$ and $N_{0.6} \%$ near-surface altitudes}

Figure 18 provides a composite map of $N_{\mathrm{CN}}$ and $N_{0.6 \%}$ for near-surface altitudes in and around the Korean Peninsula. Here, not only data analyzed in this study is presented but also data from several previous studies. It should be noted that the very same instruments were used in all but one (Yum et al., 2005) study. The measurement platforms include ground stations, ships and aircraft, and the total time span of the measurements is 8 years. For the aircraft measurements, only data below $1100 \mathrm{~m}$ altitude are considered. Although each measurement activity was conducted under different meteorological conditions, seasons and years, one can still find some general characteristics of the aerosol distributions over this region.

First, the overall $N_{\mathrm{CN}}$ and $N_{0.6 \%}$ range was 2500 $20000 \mathrm{~cm}^{-3}$ and $1000-5000 \mathrm{~cm}^{-3}$, respectively. According to a study that compiled various studies from around the globe (Andreae, 2009), such concentration levels correspond to polluted marine or continental conditions.

Second, $N_{\mathrm{CN}}$ and $N_{0.6 \%}$ over the Yellow Sea and East China Sea, although measured at least $100 \mathrm{~km}$ from land, are comparable to or even higher than those measured at island sites near the Korean Peninsula such as Baengyeongdo (J. H. Kim et al., 2011), Yeongjongdo (Kim et al., 2012) or Jeju Island (Yum et al., 2007; J. H. Kim et al., 2011). 

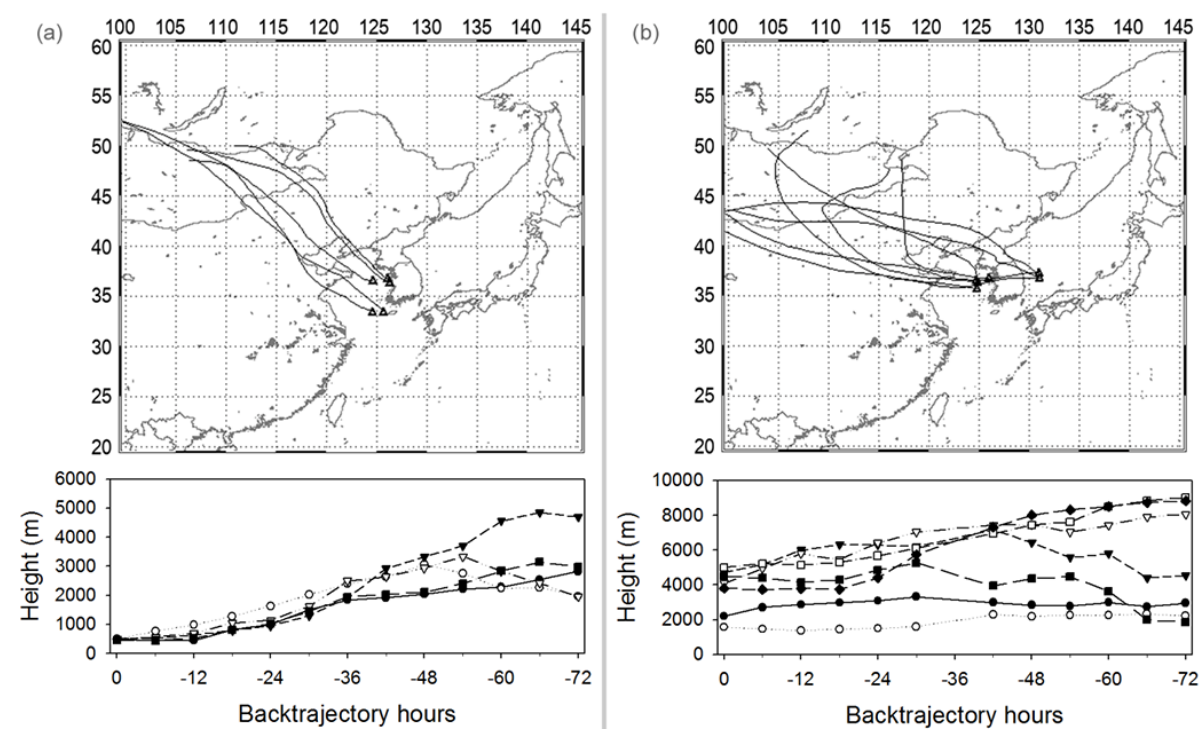

Figure 16. The 3-day back-trajectories of the air mass at the locations of low $N_{0.6 \%} / N_{\mathrm{CN}}$ vertical soundings (left) during the flight on 18 October 2009 and (right) on other days.

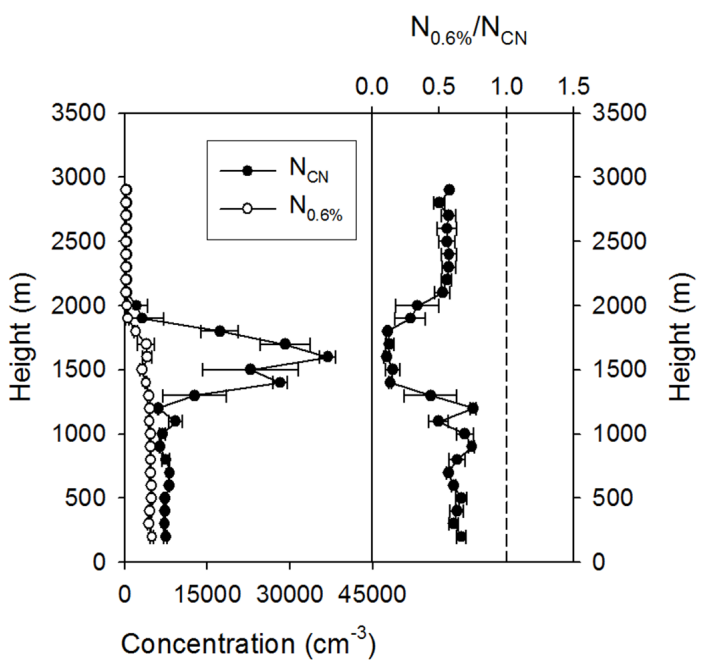

Figure 17. A typical example of low $N_{0.6 \%} / N_{\mathrm{CN}}$ layer aloft (> $1000 \mathrm{~m})$ (on 15 October 2009).

Moreover, the concentrations observed in the western part of the Korean Peninsula tend to be higher than those measured in the eastern part of the Korean Peninsula and over the East Sea, which agrees well with what Y.-J. Kim et al. (2011) found from satellite retrievals of AOD. This trend indicates that continental outflow is dominantly affecting aerosol characteristics over the region.

Third, while $N_{\mathrm{CN}}$ in Seoul are higher than $N_{\mathrm{CN}}$ at all other locations in this region by a factor of two or more, $N_{0.6 \%}$ in Seoul is not as conspicuously higher and is actually comparable to $N_{0.6 \%}$ measured at Anmyeon (Yum et al., 2005) and Baengyeongdo (J. H. Kim et al., 2011). Interest- ingly, $N_{0.6 \%}$ measured in Tokyo $\left(1760 \mathrm{~cm}^{-3}\right.$, see Kuwata and Kondo, 2008) is quite comparable to $N_{0.6 \%}$ obtained at Daegwallyeong and over the East Sea. It may be suggested that local sources in Seoul contribute dominantly to $N_{\mathrm{CN}}$ but not to $N_{0.6 \%}$ and that the majority of $\mathrm{CCN}$ in Seoul originates in continental outflow that affects the whole Korean Peninsula. Such an explanation is in accordance with the discussion in Sect. 2.2.

\section{Summary}

Total number concentrations of particles having a diameter larger than $10 \mathrm{~nm}\left(N_{\mathrm{CN}}\right)$, cloud condensation nuclei at several supersaturation values $\left(N_{\mathrm{CCN}}\right)$, and the number size distribution of particles with $10-414 \mathrm{~nm}$ diameters were measured in Seoul between 2004 and 2010. The results illustrate that concentrations are highest during winter and lowest during summer, perhaps largely due to the monsoon circulation. The elevated heating emission locally in Seoul and also in China may have contributed to the highest concentrations in winter, although no conclusive evidence is provided. Traffic emission profoundly influences the diurnal variation of $N_{\mathrm{CN}}$ but its influence on $N_{\mathrm{CCN}}$ is rather limited. In contrast, there is a strong negative relationship between $N_{\mathrm{CCN}}$ and planetary boundary layer (PBL) height $\left(N_{\mathrm{CCN}}\right.$ decreases as PBL expands) but this is not the case for $N_{\mathrm{CN}}$. Such findings suggest that a significant portion of CCN measured in Seoul may not be directly from local sources.

$N_{\mathrm{CN}}$ and $N_{\mathrm{CCN}}$ at $0.6 \%$ supersaturation $\left(N_{0.6 \%}\right)$ were measured during aircraft campaigns in 2009 and 2011. The vertical structure of $N_{\mathrm{CN}}$ and $N_{0.6 \%}$ reveals that concentrations at lower altitudes were generally higher than at 


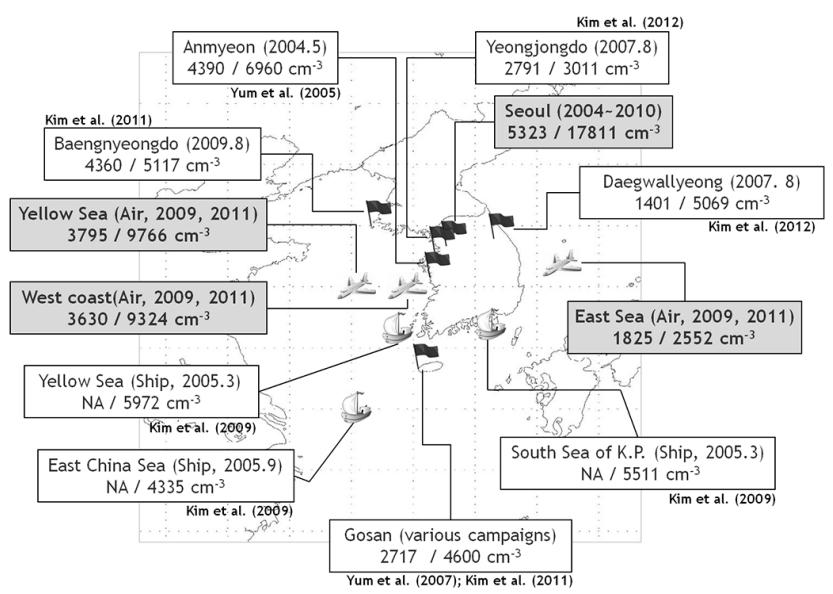

Figure 18. Composite map of the average $N_{0.6 \%}$ (before the slash) and $N_{\mathrm{CN}}$ (after the slash) measured on the ground (flag), over the sea (ship) surface or below $1100 \mathrm{~m}$ altitude (airplane) in and around the Korean Peninsula. The data presented in this study are shown in the shaded boxes.

higher altitudes, except for cases when particle formation and growth events are thought to occur at higher altitudes. $N_{\mathrm{CN}}$ and $N_{\mathrm{CCN}}$ generally show a positive correlation with aerosol scattering coefficients measured by a nephelometer but its correspondence tends to vary with altitude. Occasional instances of low $(<0.3) N_{0.6 \%} / N_{\mathrm{CN}}$ in the boundary layer are demonstrated to be associated with particle formation and growth events. With the support of ground measurements, it is confirmed that a particle formation and growth event occurred on a flight day over the Yellow Sea, and the areal extent of this event is estimated to be greater than $100 \times 450 \mathrm{~km}$.

The composite map of the aerosol distributions near the surface altitudes in and around the Korean Peninsula is constructed by combining data analyzed in this study with data presented in several previous measurement studies in this region (Fig. 18). This map is the product of 8 years of effort to measure aerosol distributions and $\mathrm{CCN}$ concentrations in this region. Considering the fact that cloud droplet concentrations are directly determined by $\mathrm{CCN}$ concentrations at cloud base altitudes and that further growth of clouds and cloud radiative properties are in turn highly dependent on cloud droplet concentrations, data shown in this map are expected to be used as a valuable reference for modeling studies that assess aerosol indirect effects in the East Asian region. The data can also be applied in the validation of satellite remote-sensing of the aerosol distributions in this region. Overall, the exhibited concentrations are representative of the values measured over polluted regions elsewhere on the globe. There is also a generally decreasing trend from west to east over the region, implying that the region is constantly under the dominant influence of continental outflow.
Acknowledgements. The authors gratefully acknowledge the NOAA Air Resources Laboratory (ARL) for the provision of the HYSPLIT transport and dispersion model and READY website (http://ready.arl.noaa.gov) used in this publication. This work is funded by the Korea Meteorological Administration Research and Development Program under Grant CATER_20123051.

Edited by: C. H. Song

\section{References}

Adhikari, M., Ishizaka, Y., Minda, H., Kazaoka, R., Jensen, J. B., Gras, G. L., and Nakajima, T.: Vertical distribution of cloud condensation nuclei concentrations and their effect on microphysical properties of clouds over the sea near the southwest islands of Japan, J. Geophys. Res., 110, D10203, doi:10.1029/2004JD004758, 2005.

Andreae, M. O.: Correlation between cloud condensation nuclei concentration and aerosol optical thickness in remote and polluted regions, Atmos. Chem. Phys., 9, 543-556, doi:10.5194/acp-9-543-2009, 2009.

Asmi, A., Wiedensohler, A., Laj, P., Fjaeraa, A.-M., Sellegri, K., Birmili, W., Weingartner, E., Baltensperger, U., Zdimal, V., Zikova, N., Putaud, J.-P., Marinoni, A., Tunved, P., Hansson, H.C., Fiebig, M., Kivekäs, N., Lihavainen, H., Asmi, E., Ulevicius, V., Aalto, P. P., Swietlicki, E., Kristensson, A., Mihalopoulos, N., Kalivitis, N., Kalapov, I., Kiss, G., de Leeuw, G., Henzing, B., Harrison, R. M., Beddows, D., O’Dowd, C., Jennings, S G., Flentje, H., Weinhold, K., Meinhardt, F., Ries, L., and Kulmala, M.: Number size distributions and seasonality of submicron particles in Europe 2008-2009, Atmos. Chem. Phys., 11, 5505-5538, doi:10.5194/acp-11-5505-2011, 2011.

Bodhaine, B. A., Ahlquist, N. C., and Schnell, R. C.: Threewavelength nephelometer suitable for aircraft measurement of background aerosol scattering coefficient, Atmos. Environ. AGen., 25, 10, 2267-2276, 1991.

Brooks, I. M.: Find boundary layer top: Application of a wavlet covariance transform to lidar backscatter profiles, J. Atmos. Ocean. Tech., 20, 1092-1105, 2003.

Buzorius, G., McNaughton, C. S., Clarke, A. D., Covert, D. S., Blomquist, B., Nielsen, K., and Brechtel, F. J.: Secondary aerosol formation in continental outflow conditions during ACE-Asia, J. Geophys. Res., 109, D24203, doi:10.1029/2004JD004749, 2004.

Carrico, C. M., Kus, P., Rood, M. J., Quinn, P. K., and Bates, T. S.: Mixtures of pollution, dust, sea salt, and volcanic aerosol during ACE-Asia: Radiative properties as a function of relative humidity, J. Geophys. Res., 108, D238650, doi:10.1029/2003JD003405, 2003.

Clarke, A. and Kapustin, V.: Hemispheric aerosol vertical profiles: Anthropogenic impacts on optical depth and cloud nuclei, Science, 329, 1488-1492, 2010.

Crutzen, P.: Albedo enhancement by stratospheric sulfur injections: A contribution to resolve a policy dilemma?, Clim. Change, 77, 211-219, doi:10.1007/s10584-006-9101-y, 2006.

Draxler, R. R. and Rolph, G. D.: HYSPLIT (HYbrid Single-Particle Lagrangian Integrated Trajectory) Model access via NOAA ARL READY Website, available at: http://ready.arl.noaa.gov/ HYSPLIT.php (last access: 23 May 2013), NOAA Air Resources Laboratory, Silver Spring, MD, USA, 2013. 
Hudson, J. G.: Observations of anthropogenic cloud condensation nuclei, Atmos. Environ. A-Gen., 25, 2449-2445, 1991.

Hudson, J. G., Xie, Y., and Yum, S. S.: Vertical distributions of cloud condensation nuclei spectra over the summertime Southern Ocean, J. Geophys. Res., 103, 16609-16624, 1998.

Hussein, T., Junninen, H., Tunved, P., Kristensson, A., Dal Maso, M., Riipinen, I., Aalto, P. P., Hansson, H.-C., Swietlicki, E., and Kulmala, M.: Time span and spatial scale of regional new particle formation events over Finland and Southern Sweden, Atmos. Chem. Phys., 9, 4699-4716, doi:10.5194/acp-9-4699-2009, 2009.

IPCC: Climate Change 2007: The Physical Science Basis, Contribution of Working Group I to the Fourth Assessment Report of the Intergovernmental Panel on Climate Change, edited by: Solomon, S., Qin, D., Manning, M., Chen, Z., Marquis, M., Averyt, K. B., Tignor, M., and Miller, H. L., Cambridge University Press, Cambridge, 1056 pp., 2007.

Kiehl, J. T.: Twentieth century climate model response and climate sensitivity, Geophys. Res. Lett., 34, L22710, doi:10.1029/2007GL031383, 2007.

Kim, J.: Transport routes and source regions of Asian dust observed in Korea during the past 40 years (1965-2004), Atmos. Environ., 42, 4778-4789, 2008.

Kim, J. H., Yum, S. S., Lee, Y.-G., and Choi, B.-C.: Ship measurements of submicron aerosol size distributions over the Yellow Sea and the East China Sea, Atmos. Res., 93, 700-714, 2009.

Kim, J. H., Yum, S. S., Shim, S., Yoon, S.-C., Hudson, J. G., Park, J., and Lee, S.-J.: On aerosol hygroscopicity, cloud condensation nuclei $(\mathrm{CCN})$ spectra and critical supersaturation measured at two remote islands of Korea between 2006 and 2009, Atmos. Chem. Phys., 11, 12627-12645, doi:10.5194/acp-1112627-2011, 2011.

Kim, J. H., Park, M., Shim, S., and Yum, S. S.: On the contrast of aerosol size distribution and cloud condensation nuclei concentrations between the east and the west of the Korean Peninsula, Atmosphere, 22, 87-96, 2012 (in Korean).

Kim, S.-W., Yoon, S.-C., Won, J.-G., and Choi, S.-C.: Ground-based remote sensing measurements of aerosol and ozone in an urban area: A case study of mixing height evolution and its effect on ground-level ozone concentrations, Atmos. Environ., 41, 70697081, 2007.

Kim, Y., Yoon, S.-C., Kim, S.-W., Kim, K.-Y., Lim, H.-C., and Ryu, J.: Observation of new particle formation and growth events in Asian continental outflow, Atmos. Environ., 64, 160-168, 2013.

Kim. Y.-J., Lee, J.-H., and Kim, B.-G.: An Analysis of AerosolCloud Relationship Using MODIS and NCEP/NCAR Reanalysis Data around Korea, J. Korean Soc. Atmos. Environ., 27, 152167, 2011 (in Korean).

Kuwata, M. and Kondo, Y.: Dependence of size-resolved CCN spectra on the mixing state of nonvolatile cores observed in Tokyo, J. Geophys. Res., 113, D19202, doi:10.1029/2007JD009761, 2008.

Kumala, M., Vehkamaki, H. Petaja, T., Dal Maso, M., Lauri, A., Kerminen, V.-M., Birmili, W., and McMurry, P. H.: Formation and growth rates of ultrafine atmospheric particles: a review of observations, J. Aerosol Sci., 35, 143-176, 2004.

Kuwata, M., Kondo, Y., Miyazaki, Y., Komazaki, Y., Kim, J. H., Yum, S. S., Tanimoto, H., and Matsueda, H.: Cloud condensation nuclei activity at Jeju Island, Korea in spring 2005, At- mos. Chem. Phys., 8, 2933-2948, doi:10.5194/acp-8-2933-2008, 2008.

Lee, Y.-G., Lee, H.-W., Kim, M. S., Choi, C. Y., and Kim, J.: Characteristics of particle formation events in the coastal region of Korea in 2005, Atmos. Environ., 42, 3729-3739, 2008.

Matsumoto, K., Tanaka, H., Nagao, I., and Ishizaka, Y.: Contribution of particulate sulfate and organic carbon to cloud condensation nuclei in the marine atmosphere, Geophys. Res. Lett., 24, 665-658, 1997.

McNaughton, C. S., Clarke, A. D., Howell, S. G., Moore II, K. G., Brekhovskikh, V., Weber, R. J., Orsini, D. A., Covert, D. S., Buzorius, G., Brechtel, F. J., Carmichael, G. R., Tang, Y., Eisele, F. L., Mauldin, R. L., Bandy, A. R., Thornton, D. C., and Blomquist, B.: Spatial distribution and size evolution of particles in Asian outflow: significance of primary and secondary aerosols during ACE-Asia and TRACE-P, J. Geophys. Res., 109, D19S06, doi:10.1029/2003JD003528, 2004.

Mochida, M., Nishita-Hara, C., Kitamori, Y., Aggarwal, S. G., Kawamura, K., Miura, K., and Takami, A.: Size-segregated measurements of cloud condensation nucleus activity and hygroscopic growth for aerosols at Cape Hedo, Japan, in spring 2008, J. Geophys. Res., 115, D21207, doi:10.1029/2009JD013216, 2010.

Mönkkönen, P., Koponen, I. K., Lehtinen, K. E. J., Hämeri, K., Uma, R., and Kulmala, M.: Measurements in a highly polluted Asian mega city: observations of aerosol number size distribution, modal parameters and nucleation events, Atmos. Chem. Phys., 5, 57-66, doi:10.5194/acp-5-57-2005, 2005.

Pandey, S. K., Kim, K.-H., Chung S.-Y., Cho, S.-J., Kim, M.-Y., and Sho, Z.-H.: Long-term study of $\mathrm{NO}_{\mathrm{X}}$ behavior at urban roadside and background locations in Seoul, Korea, Atmos. Environ., 42, 607-622, 2008.

Park, K., Park., J. Y., Kwak, J.-H., Cho, G. N., and Kim, J.-S.: Seasonal and diurnal variations of ultrafine particle concentration in urban Gwangju, Korea: Observation of ultrafine particle events, Atmos. Environ., 42, 788-799, 2008.

Roberts, G. C. and Nenes, A.: A continuous-flow streamwise thermal-gradient CCN chamber for atmospheric measurements, Aerosol Sci. Tech., 39, 206-221, 2005.

Robock, A.: 20 reasons why geoengineering may be a bad idea, B. Atom. Sci., 64, 14-18, 2008.

Rogelj, J., Hare, W., Lowe, J., van Vuuren, D. P., Riahi, K., Matthews, B., Hanaoka, T., Jiang, K., and Meinshausen, M.: Emission pathways consistent with a $2^{\prime} \mathrm{C}$ global temperature limit, Nature Climate Change, 1, 413-418, 2011.

Rolph, G. D.: Real-time Environmental Applications and Display sYstem (READY) Website, available at: http://ready.arl.noaa.gov (last access: 23 May 2013), NOAA Air Resources Laboratory, Silver Spring, MD, 2013.

Rose, D., Nowak, A., Achtert, P., Wiedensohler, A., Hu, M., Shao, M., Zhang, Y., Andreae, M. O., and Pöschl, U.: Cloud condensation nuclei in polluted air and biomass burning smoke near the mega-city Guangzhou, China - Part 1: Size-resolved measurements and implications for the modeling of aerosol particle hygroscopicity and CCN activity, Atmos. Chem. Phys., 10, 33653383, doi:10.5194/acp-10-3365-2010, 2010.

Schwartz, S. E., Charlson, R. J., Khan, R. A., Ogren, J. A., and Rodhe, H.: Why Hasn't Earth Warmed as Much as Expected?, J. Climate, 23, 2453-2464, 2010. 
Shim, S., Yoon, Y. J., Yum, S. S., Cha, J. W., Kim, J. H., Kim, J., and Lee, B.-Y.: Nephelometer measurement of aerosol scattering coefficient at Seoul, Atmosphere, 18, 459-474, 2008 (in Korean).

Song, M., Lee, M., Kim, J. H., Yum, S. S., Lee, G., and Kim, K.-R.: New particle formation and growth in relation to vertical mixing and chemical species during ABC-EAREX2005, Atmos. Res., 97, 359-370, 2010.

Weber, R. J., Lee, S., Chen, G., Wang, B., Kapustin, V., Moore, K., Clarke, A. D., Mauldin, L., Kosciuch, E., Cantrell, C., Eisele, F., Thornton, D. C., Bandy, A. R., Sachse, G. W., and Fuelberg, H. E.: New particle formation in anthropogenic plumes advecting from Asia observed during TRACE-P, J. Geophys. Res., 108, 8814, doi:10.1029/2002JD003112, 2003.

Wiedensohler, A., Cheng, Y. F., Nowak, A., Wehner, B., Achtert, P., Berghof, M., Birmili, W., Wu, Z. J., Hu, M., Zhu, T., Takegawa, N., Kita, K., Kondo, Y., Lou, S. R., Hofzumahaus, A., Holland, F., Wahner, A., Gunthe, S. S. Rose, D., Su, H., and Pöschl, U.: Rapid aerosol particle growth and increase of cloud condensation nucleus activity by secondary aerosol formation and condensation: A case study for regional air pollution in northeastern China, J. Geophys. Res., 114, D00G08, doi:10.1029/2008JD010884, 2009.
Wu, Z., Hu, M., Liu, S., Wehner, B., Bauer, S., Maßling, A., Wiedensohler, A., Petäjä, T., Maso, M. D., and Kulmala, M.: New particle formation in Beijing, China: statistical analysis of a 1-year data set, J. Geophys. Res., 112, D09209, doi:10.1029/2006JD007406, 2007.

Yum, S. S., Hudson, J. G., Song, K. Y., and Choi, B.C.: Springtime cloud condensation nuclei concentrations on the west coast of Korea, Geophys. Res. Lett., 32, L09814, doi:10.1029/2005GL022641, 2005.

Yum, S. S., Roberts, G., Kim, J. H., Song, K., and Kim, D.: Submicron aerosol size distributions and cloud condensation nuclei concentrations measured at Gosan, Korea, during the Atmospheric Brown Clouds-East Asian Regional Experiment 2005, J. Geophys. Res., 112, D22S32, doi:10.1029/2006JD008212, 2007.

Zhang, Z. Q. and Liu, B. Y. H.: Performance of TSI 3760 CNC at reduced pressures and flow rates, Aerosol Sci. Tech., 15, 228238, 1991. 